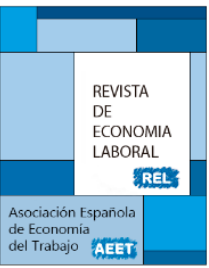

\title{
LAS REFORMAS DIRIGIDAS A LA FLEXIBILIDAD INTERNA DE LAS EMPRESAS: SUSPENSIÓN DE CONTRATOS Y REDUCCIÓN DE JORNADA
}



\author{
Carlos García-Serrano ${ }^{1}$ \\ Universidad de Alcalá
}

Recibido Julio 2015; Aceptado Octubre 2015

\section{Resumen}

El objetivo del artículo consiste en presentar los cambios normativos adoptados en las últimas reformas laborales relacionados con el procedimiento y con los incentivos para la utilización de medidas vinculadas a Expedientes de Regulación de Empleo (ERE) de suspensión de contratos y de reducción de jornada como alternativa a los despidos a la hora realizar ajustes en la utilización del factor trabajo. Además, dado que estos cambios fueron simultáneos a otros cuyo objeto era facilitar los procedimientos del despido y otros tipos de medidas de flexibilidad interna de las empresas, se trata de saber si dichas modificaciones normativas han podido tener algún impacto sobre la propensión de las empresas a utilizar dichas medidas de suspensión y de reducción en vez de los despidos y sus posibles efectos sobre el mantenimiento del empleo.

Palabras clave: Expedientes de Regulación de Empleo, flexibilidad interna, suspensión de contratos, reducción de jornada.

Clasificación JEL: J23, J63, J65.

\section{Abstract}

The aim of this paper is to present the legal changes passed in the last labour market reforms concerning the procedure and the incentives for using short-time work programmes (temporary layoffs and working time reduction) as an alternative to permanent layoffs when firms have to carry out adjustments in the use of labour. Moreover, since these changes were simultaneous to other ones whose objective was to facilitate the procedures of permanent layoffs and still other measures for internal flexibility of firms, we try to know whether those legal modifications have brought about some sort of impact on the proneness of firms to use such measures of temporary layoffs and reduction of working time instead of permanent layoffs and their potential impact on employment stability.

Key words: Short-time work programmes, Internal flexibility, Temporary layoffs, Working time reduction.

JEL Classification: J23, J63, J65.

\footnotetext{
1 El autor agradece la financiación del Ministerio de Economía y Competitividad (proyecto ECO2014-57623-R) así como los comentarios de un evaluador anónimo y del profesor Brick O. Lage. Autor para correspondencia: carlos.garcia@uah.es .
}

C Revista de Economía Laboral 


\section{Introducción}

Los programas de reparto temporal del trabajo son instrumentos de protección del empleo que tratan de evitar los despidos de trabajadores en casos de caída de la demanda de bienes y servicios o de crisis temporales. Las empresas que los utilizan pueden reducir total o parcialmente la jornada de trabajo de una parte o de la totalidad de los empleados pero manteniendo la relación contractual con los mismos. A su vez, los trabajadores reciben una compensación (en forma de prestaciones por desempleo) por las horas no trabajadas y la reducción de sus ingresos salariales. El objetivo de estos programas es permitir que las empresas, ante una reducción de la demanda de productos o de las ventas, no ajusten el trabajo que emplean a través del margen extensivo (el volumen de trabajadores ocupados) sino a través del margen intensivo (el número medio de horas por trabajador). $\mathrm{O}$ dicho de otra manera, que no utilicen la flexibilidad externa (vía despidos) sino la flexibilidad interna (vía horas de trabajo y salarios). Si esto fuese así, el nivel de empleo sería menos sensible a las variaciones de la producción agregada, de modo que ante una reducción del PIB la ocupación disminuiría menos que en ausencia de los programas de reparto del trabajo.

Estos programas han recibido una gran atención en la reciente recesión, puesto que algunos analistas han considerado que el relativo éxito de algunos países en cuanto al reducido efecto que la caída de la producción ha tenido sobre el empleo y el paro (como en el caso de Alemania) puede achacarse en buena medida a la influencia de este tipo de programas (Brenke et al., 2013).

En el caso de España, éstos se plasman formalmente en la adopción por parte de las empresas de medidas relacionadas con Expedientes de Regulación de Empleo (ERE) de suspensión de contratos y de reducción de jornada como alternativa a los despidos a la hora realizar ajustes en la utilización del factor trabajo. El incremento de su uso durante la última recesión puede haberse debido no solo al brusco cambio en las condiciones económicas que se produjo a partir de 2008 sino también a las modificaciones normativas. Estas se han plasmado en cambios relacionados con el procedimiento (introducidos con las reformas de 2010 -Ley 35/2010, de 17 de septiembre, de medidas urgentes para la reforma del mercado de trabajo- y 2012 -Ley 3/2012, de 6 de julio, de medidas urgentes para la reforma del mercado laboral-) así como en aumentos de los incentivos económicos (Real Decreto Ley 2/2009, de 6 de marzo, de medidas urgentes para el mantenimiento y el 
fomento del empleo y la protección de las personas desempleadas y Ley 27/2009, de 30 de septiembre, de igual nombre). El objetivo de dichas modificaciones ha sido fomentar la adopción de EREs de suspensión de contratos y de reducción de jornada mediante la flexibilización del procedimiento y las causas para su puesta en marcha, la bonificación de las cuotas empresariales a la Seguridad Social de los trabajadores afectados por los mismos y la reposición de las prestaciones por desempleo a dichos trabajadores. ${ }^{2}$

El propósito de este artículo consiste en presentar las principales modificaciones normativas que se han producido en los últimos años en este ámbito y tratar de examinar si han producido algún cambio en su uso por parte de las empresas. Para entender adecuadamente su posible influencia, las modificaciones que afectan a los EREs de suspensión de contratos y de reducción de jornada se enmarcan en los cambios más amplios que se han producido en los ámbitos de la regulación de las medidas de flexibilidad interna de las empresas (condiciones de trabajo, movilidad geográfica y funcional, etc.) y de los despidos.

La estructura del artículo es la siguiente. En la sección dos se presenta la evolución de la normativa de los EREs de suspensión de contratos y de reducción de jornada, tanto en lo que respecta a los cambios en el procedimiento y las causas como en lo relativo a los incentivos económicos. En la sección tres se examinan las modificaciones que afectan a las medidas de flexibilidad interna y los despidos. En la sección cuatro se proporcionan algunos datos sobre el uso de dichos procedimientos y sobre el posible efecto de las modificaciones normativas. Finalmente, la sección cinco ofrece un resumen y las conclusiones.

\section{Evolución de la normativa sobre suspensión de contratos y reducción de jornada}

El artículo 47 del Estatuto de los Trabajadores (ET) legitima al empresario para suspender los contratos de trabajo y reducir la jornada si concurren "causas económicas, organizativas, técnicas o de producción”. El elemento diferencial de estas medidas, frente al despido colectivo, es su temporalidad. Si bien están vinculadas a situaciones de crisis empresarial que aconsejan una paralización de la actividad o una reducción de la actividad ordinaria de la empresa, su finalidad es la

\footnotetext{
2 Una descripción de las modificaciones introducidas en dichos cambios normativos que han afectado a la suspensión del contrato y la reducción de jornada puede encontrarse en Del Rey (2010) y Garrido Pérez (2012).
} 
recuperación económica, la superación de la crisis y, en consecuencia, la revocación de las medidas de suspensión o reducción de jornada planteadas. Se trata, por tanto, de medidas coyunturales que no tienen por qué producir consecuencias definitivas (extintivas) en los contratos de los trabajadores afectados.

Entre la suspensión del contrato y la reducción de jornada existen ciertas diferencias, sobre todo desde un punto de vista conceptual. Esto ha llevado a su tratamiento individualizado en la normativa, abordando la suspensión del contrato de trabajo en el artículo 47.1 del ET y la reducción de jornada en el artículo 47.2 (la introducción explícita de la medida de reducción temporal de jornada se produjo con la reforma de 2010). En cuanto al contenido de las mismas, la primera de las medidas conlleva una suspensión del contrato de trabajo, es decir, una paralización de la actividad laboral dentro de los periodos de referencia, mientras que la reducción de la jornada sólo supone una minoración temporal de la jornada del trabajador durante los periodos de referencia. Sin embargo, a pesar de sus diferencias conceptuales, el procedimiento para llevar a cabo ambos tipos de medidas de flexibilidad interna es el mismo. El cuadro 1 presenta un resumen de las características del mismo y de los cambios experimentados en las últimas dos reformas, todo lo cual se examina a continuación.

\subsection{El procedimiento}

El procedimiento que las empresas debían seguir para llevar a cabo medidas de este tipo referidas a un grupo de trabajadores (que afectase a un $10 \%$ de la plantilla, al menos) debía enmarcase en un ERE y apenas sufrió cambios desde la reforma laboral de 1994 hasta la de 2012 (salvo algunas modificaciones introducidas en la reforma de 2010). A partir de 1994 (Ley 11/1994, de 19 de mayo, por la que se modifican determinados artículos del Estatuto de los Trabajadores, y del texto articulado de la Ley de Procedimiento Laboral y de la Ley sobre Infracciones y Sanciones en el Orden Social), se hizo una distinción entre despidos individuales y colectivos: las razones económicas fueron aceptadas como base legal para los despidos individuales (reconociendo lo que era práctica habitual) y los EREs quedaron restringidos a los despidos colectivos así como a las suspensiones colectivas de contratos y las reducciones de jornada. Además, se trató de simplificar el procedimiento y reducir los plazos de resolución: se dio mayor peso a la negociación y se limitó el papel de la autoridad laboral; a cambio, el empresario tenía que proporcionar 
información sobre la situación económica de la empresa al comienzo del proceso y preparar, para aquellas de 50 trabajadores o más, un "plan social”.

El procedimiento era como sigue. Para iniciar un ERE, el empresario tenía que abrir un periodo mínimo de consultas y negociación con los representantes de los trabajadores de 30 días con objeto de llegar a un acuerdo con ellos, a la vez que la empresa tenía que notificarlo a la autoridad laboral, proporcionando la información necesaria para justificar las medidas propuestas. Tras el periodo de consultas, se podían dar las siguientes posibilidades:

- Se alcanzaba un acuerdo. En este caso, la autoridad laboral simplemente lo certificaba en 15 días.

- Si no se alcanzaba un acuerdo, la autoridad laboral disponía de 15 días para tomar una decisión, con el añadido de que si esta no se producía en dicho plazo el ERE era considerado autorizado. Si el ERE era rechazado, sería devuelto a la empresa con la recomendación de que se alcanzase un acuerdo con los trabajadores. $^{3}$

Este procedimiento era común para todos los tipos de EREs, siendo las únicas peculiaridades que, en el caso de suspensiones de contratos y reducciones de jornada, se producía una limitación del plazo para la respuesta de la autoridad laboral a la mitad de su duración y una reducción de la documentación justificativa a la estrictamente necesaria. Adicionalmente, no existía exigibilidad de la indemnización a la empresa, puesto que los trabajadores no eran despedidos y continuaban ligados contractualmente a la misma. Además, los trabajadores, ya fueran despedidos, suspendidos temporalmente o su jornada reducida, tenían derecho a recibir las prestaciones por desempleo, siempre que hubieran realizado las contribuciones mínimas necesarias para ello. La diferencia era que los trabajadores suspendidos o en reducción de jornada solo recibirían unas prestaciones proporcionales al tiempo dejado de trabajar: en el caso de las suspensiones de empleo por los días completos, continuados o alternos,

\footnotetext{
${ }^{3} \mathrm{El}$ caso más frecuente era que las empresas y los trabajadores llegasen a un acuerdo y la autoridad laboral lo autorizase (más de tres de cada cuatro EREs). Además, la proporción de EREs no acordados pero autorizados posteriormente por la autoridad laboral también era elevada (tres de cada cuatro). Estos datos se refieren al número de EREs y son un promedio de lo que sucedió en las décadas de 1990 y 2000 basados en la información procedente de la "Estadística de Regulación de Empleo" publicada por el Ministerio de Empleo y Seguridad Social (anteriormente Ministerio de Trabajo).
} 
de suspensión; en el caso de la reducción temporal de jornada, por la parte proporcional de reducción de la jornada diaria ordinaria de trabajo (para la que además se establecía un umbral mínimo de reducción de una tercera parte de las horas normales de trabajo para tener derecho a recibir prestaciones). Estas prestaciones se pagaban con cargo a las prestaciones potenciales acumuladas por los trabajadores. Podía suceder, por tanto, que en el caso de ser despedido un trabajador pudiera haber agotado una parte de sus prestaciones en episodios anteriores de despido, de suspensión o de reducción de jornada.

En resumen, antes de la reforma de 2012 las medidas de suspensión de contratos y reducción de jornada (también las de despido colectivo) se materializaban a través de un procedimiento administrativo en sentido estricto, en donde debía obtenerse una autorización de la autoridad laboral. Dicha autorización administrativa condicionaba, en principio, la posibilidad de adopción de estas medidas por el empresario. Sin embargo, la reforma aplicada por la Ley 3/2012 ha supuesto un cambio sustancial en el procedimiento, ya que no solo ha eliminado la autorización administrativa sino que ha pretendido orientar el mismo a fomentar la negociación entre el empresario y la representación legal de los trabajadores en el preceptivo periodo de consultas, situando la participación de la autoridad laboral en un segundo plano respecto del predominio que ostentaba en el procedimiento anterior. El reglamento desarrollado en el Capítulo II del Real Decreto 1483/2012, de 29 de octubre, se adoptó con el objetivo de adecuar los procedimientos de despido colectivo y de suspensión de contratos y reducción de jornada a las novedades introducidas por la reforma laboral aprobada en julio de 2012.4

Comenzando por las causas, el procedimiento para la suspensión de los contratos de trabajo o la reducción de la jornada podrá promoverse por el empresario cuando concurran causas económicas, técnicas, organizativas o de producción (artículo 16 del RD 1483/2012). El empresario podrá acudir a este procedimiento cuando la crisis empresarial tenga sus causas en factores de carácter temporal y el

\footnotetext{
${ }^{4}$ La reforma laboral de 2010 apenas alteró las características de este tipo de medidas, si bien trató de aumentar su uso eliminando algunas restricciones, estableciendo que el procedimiento será aplicable "cualquiera que sea el número de trabajadores de la empresa y del número de afectados por la suspensión" (antes había establecido un porcentaje mínimo del 10\%) y ampliando el concepto de reducción de jornada por dichas causas para recoger "la disminución temporal de entre un $10 \%$ y un $70 \%$ de la jornada de trabajo computada sobre la base de una jornada diaria, semanal, mensual o anual" (antes había establecido también un porcentaje mínimo de una tercera parte).
} 
procedimiento de suspensión o reducción contribuya a superar la difícil situación o, al menos, permitir una mejora.

En este marco, las causas deben ligarse a las previstas para el despido colectivo (artículo 51 del ET). Concurren causas económicas cuando de los resultados de la empresa se desprenda una situación económica negativa, en casos tales como la existencia de pérdidas actuales o previstas, o la disminución persistente de su nivel de ingresos ordinarios o ventas. En todo caso, se entenderá que la disminución es persistente si durante dos trimestres consecutivos el nivel de ingresos ordinarios o ventas de cada trimestre es inferior al registrado en los mismos trimestres del año anterior. Aquí es necesario realizar dos precisiones. En primer lugar, respecto al concepto de disminución persistente, ya que ésta existirá si hay una reducción de ingresos durante dos trimestres consecutivos frente a los tres trimestres que recoge el artículo 51 para los despidos colectivos. En segundo lugar, hay que tener en cuenta que se trata de una lista abierta, es decir, el empresario podrá alegar otras circunstancias para acreditar las pérdidas o la disminución de ingresos, aunque no se encuentren expresamente citadas en el precepto. Las restantes causas previstas para la suspensión del contrato o la reducción de la jornada (técnicas, organizativas o de producción) son las mismas que las referidas al despido colectivo, refiriéndose a situaciones inherentes a la empresa y que guardan relación con su actividad, su funcionamiento o su organización interna.

Por lo que respecta al procedimiento, este se iniciará por escrito, mediante comunicación del inicio del periodo de consultas dirigido por el empresario a los representantes legales de los trabajadores. La comunicación deberá contener los siguientes extremos:

- Especificación de las causas que motivan la suspensión del contrato o la reducción de jornada, lo que implica que habrá que determinar cuál de las causas que se han mencionado más arriba concurren en el supuesto concreto y explicar brevemente el impacto que la misma está teniendo en la actividad empresarial. Se trata de otorgar a la representación legal de los trabajadores una visión real y actual de la crisis empresarial que da origen al procedimiento.

- Número y clasificación profesional de los trabajadores afectados. Cuando el procedimiento afecte a más de un centro de trabajo, esta información deberá estar desglosada por centro de trabajo y, en su caso, provincia y comunidad autónoma. 
- Número y clasificación profesional de los trabajadores empleados habitualmente en el último año (con las mismas precisiones que el punto anterior).

- Concreción y detalle de las medidas y los trabajadores afectados.

\section{Cuadro 1: Resumen de las características de los EREs de suspensión de contratos y reducción de jornada}

\begin{tabular}{|c|c|c|c|}
\hline Aspecto & $\begin{array}{c}\text { Situación tras la } \\
\text { reforma de } 1994 \\
\end{array}$ & Reforma de 2010 & Reforma de 2012 \\
\hline $\begin{array}{l}\text { Grupo de } \\
\text { trabajadores } \\
\text { afectado }\end{array}$ & $\begin{array}{l}\text { Al menos: } \\
\text { - } 10 \text { trabajadores en } \\
\text { empresas de menos } \\
\text { de } 100 \\
-10 \% \text { en las de } 100- \\
300 \\
-30 \text { en las de } 300 \text { o } \\
\text { más }\end{array}$ & $\begin{array}{l}\text { Cualquiera que sea el } \\
\text { número de trabajadores } \\
\text { de la empresa y el } \\
\text { número de afectados por } \\
\text { la suspensión }\end{array}$ & Igual \\
\hline $\begin{array}{l}\text { Límites a la } \\
\text { reducción de } \\
\text { jornada }\end{array}$ & $\begin{array}{l}\text { Umbral mínimo de } \\
1 / 3 \text { de las horas } \\
\text { normales de trabajo }\end{array}$ & $\begin{array}{l}\text { Entre un } 10 \% \text { y un } 70 \% \\
\text { de la jornada de trabajo } \\
\text { computada sobre la base } \\
\text { de una jornada diaria, } \\
\text { semanal, mensual o anual }\end{array}$ & Igual \\
\hline $\begin{array}{l}\text { Causas } \\
\text { alegadas }\end{array}$ & $\begin{array}{l}\text { Económicas, técnicas, } \\
\text { organizativas o de } \\
\text { producción, para la } \\
\text { superación de una } \\
\text { situación de carácter } \\
\text { coyuntural }\end{array}$ & $\begin{array}{l}\text { Igual, pero las causas } \\
\text { económicas hacen } \\
\text { referencia a la existencia } \\
\text { de pérdidas actuales o } \\
\text { previstas o la disminución } \\
\text { persistente del nivel de } \\
\text { ingresos de la empresa }\end{array}$ & $\begin{array}{l}\text { Igual, pero las causas } \\
\text { económicas hacen } \\
\text { referencia a pérdidas } \\
\text { actuales o previstas o } \\
\text { disminución persistente } \\
\text { del nivel de ingresos } \\
\text { ordinarios o ventas } \\
\text { durante dos trimestres } \\
\text { consecutivos }\end{array}$ \\
\hline $\begin{array}{l}\text { Inicio del } \\
\text { procedimiento }\end{array}$ & $\begin{array}{l}\text { Solicitud a la } \\
\text { autoridad laboral y } \\
\text { apertura de consultas } \\
\text { con los } \\
\text { representantes de los } \\
\text { trabajadores }\end{array}$ & Igual & $\begin{array}{l}\text { Se elimina la solicitud a la } \\
\text { autoridad laboral }\end{array}$ \\
\hline $\begin{array}{l}\text { Periodo de } \\
\text { consultas }\end{array}$ & $\begin{array}{l}\text { No inferior a } 30 \text { días } \\
\text { (15 días en empresas } \\
\text { de menos de } 50 \\
\text { trabajadores) }\end{array}$ & $\begin{array}{l}\text { Los periodos anteriores } \\
\text { pasan a ser máximos en } \\
\text { vez de mínimos }\end{array}$ & 7 días \\
\hline $\begin{array}{l}\text { Procedimiento: } \\
\text { autorización } \\
\text { administrativa }\end{array}$ & $\begin{array}{l}\text { Tras el periodo de } \\
\text { consultas: } \\
\text { - Acuerdo: la } \\
\text { autoridad laboral lo } \\
\text { certificaba en } 7 \text { días } \\
\text { - Sin acuerdo: la } \\
\text { autoridad laboral } \\
\text { tenía } 7 \text { días para } \\
\text { tomar una decisión }\end{array}$ & Igual & $\begin{array}{l}\text { Se elimina la autorización } \\
\text { administrativa. A falta de } \\
\text { acuerdo el empresario } \\
\text { podrá decidir las medidas } \\
\text { a adoptar }\end{array}$ \\
\hline
\end{tabular}




\begin{tabular}{|c|c|c|c|}
\hline $\begin{array}{l}\text { Incentivos } \\
\text { económicos }\end{array}$ & Ninguno & $\begin{array}{l}\text { Medidas adoptadas en } \\
2009 \text { refrendadas en la } \\
\text { reforma de 2010: } \\
\text { - Bonificación del } 50 \% \text { de } \\
\text { cuotas empresariales a la } \\
\text { Seguridad Social ( } 80 \% \\
\text { con la reforma si hay } \\
\text { actividades formativas o } \\
\text { de otro tipo) } \\
\text { - Reposición de las } \\
\text { prestaciones por } \\
\text { desempleo } \\
\text { La empresa está obligada } \\
\text { a mantener el empleo } \\
\text { durante al menos un año } \\
\text { (seis meses con la } \\
\text { reforma) }\end{array}$ & $\begin{array}{l}\text { Se elimina el incentivo } \\
\text { adicional del } 80 \% \text { y se } \\
\text { sitúa en un año el } \\
\text { compromiso de } \\
\text { mantenimiento del } \\
\text { empleo }\end{array}$ \\
\hline
\end{tabular}

- Criterios tenidos en cuenta para la designación de los trabajadores afectados por las medidas.

- Toda esta documentación deberá ir acompañada de una memoria explicativa de las causas de la suspensión de contratos o la reducción de jornada y los restantes aspectos relacionados con este apartado, teniendo en cuenta las siguientes precisiones:

- Cuando la causa aducida por la empresa sea de índole económica, la documentación a entregar a los representantes de los trabajadores deberá incluir las cuentas anuales del último ejercicio económico completo, así como las cuentas provisionales resultantes al inicio del procedimiento.5

- Cuando la situación económica negativa alegada consista en una previsión de pérdidas, el empresario deberá informar de los criterios utilizados para su estimación y presentar un informe técnico sobre el volumen y el carácter permanente o transitorio de esa previsión de pérdidas basado en datos obtenidos a través de las cuentas anuales, de los datos del sector al que pertenece la empresa, de la evolución del mercado y de la posición de la empresa en el mismo o de cualesquiera otros que puedan acreditar esta previsión.

\footnotetext{
5 Estas cuentas deberán estar integradas por el balance de situación, cuentas de pérdidas y ganancias, estado de cambios en el patrimonio neto, estado de flujos de efectivos, memoria del ejercicio e informe de gestión o, en su caso, cuenta de pérdidas y ganancias abreviada, y balance y estado de cambios en el patrimonio neto abreviados, debidamente auditados en el caso de empresas obligadas a realizar auditorías.
} 
- Cuando la situación económica negativa alegada consista en la disminución persistente del nivel de ingresos o ventas el empresario deberá aportar, además de las cuentas anuales del último ejercicio económico completo y las cuentas provisionales al inicio del procedimiento, la documentación fiscal o contable acreditativa de la disminución persistente del nivel de ingresos ordinarios o ventas durante, al menos, los dos trimestres consecutivos inmediatamente anteriores a la fecha de la comunicación de inicio del procedimiento de suspensión de contratos o reducción de jornada, así como la correspondiente a los mismos trimestres del año anterior.

- Cuando se aleguen causas técnicas, organizativas o de producción, la documentación debe incluir una memoria explicativa y los informes técnicos que acrediten su concurrencia.

La comunicación del inicio de periodo de consultas y la documentación descrita con anterioridad deben remitirse de manera conjunta y simultánea a la autoridad laboral competente, que podrá ser la de la Administración General del Estado o de la Comunidad Autónoma correspondiente. A estos efectos, cuando el procedimiento afecte a trabajadores que desarrollen su actividad o que se encuentren adscritos a centros de trabajo ubicados en su totalidad dentro del territorio de una Comunidad Autónoma, tendrá la consideración de autoridad laboral competente el órgano que determine la comunidad respectiva. Sin embargo, será reconocida como competente la Dirección General de Empleo del Ministerio de Empleo y Seguridad Social cuando los trabajadores afectados desarrollen su actividad o se encuentren adscritos a centros de trabajo ubicados en el territorio de dos o más comunidades. ${ }^{6}$

El empresario también ha de remitir a la autoridad laboral información sobre la composición de la representación de los trabajadores, sobre la comisión que en su caso cubra la ausencia de representación legal y sobre la comisión negociadora de la propuesta empresarial, especificando si dicha negociación se desarrolla para el

\footnotetext{
${ }^{6}$ Hay una excepción a este criterio: cuando el procedimiento afecte a trabajadores que desarrollen su actividad en centros de trabajo situados en el territorio de dos o más comunidades, pero al menos el $85 \%$ de su plantilla radique en el ámbito territorial de la misma comunidad y existan trabajadores afectados en la misma, corresponderá a la autoridad laboral competente de esa comunidad, quién realizará la totalidad de las actuaciones del procedimiento.
} 
conjunto de la empresa o de forma diferenciada según cada centro de trabajo.

La autoridad laboral deberá dar traslado de dicha información y documentación a la entidad gestora de las prestaciones por desempleo y a la Inspección de Trabajo y Seguridad Social. Igualmente, si la autoridad laboral observase que la comunicación empresarial no reúne los requisitos exigidos anteriormente, lo advertirá oportunamente al empresario, a la representación legal de los trabajadores y a la Inspección de Trabajo. Esta advertencia no supondrá la paralización ni la suspensión del procedimiento, que transcurrirá según los plazos prescritos.

\subsection{Periodo de consultas}

El periodo de consultas tiene por objeto llegar a un acuerdo entre la empresa y los representantes de los trabajadores sobre las medidas de suspensión de contratos o reducción de jornada. El periodo tendrá una duración no superior a 15 días y puede ser sustituido, siempre que exista común acuerdo entre las partes, por los procedimientos de mediación y arbitraje que sean de aplicación en el ámbito de la empresa, en particular los regulados en los acuerdos sobre solución extrajudicial de conflictos laborales de nivel estatal o autonómico (artículo 28 del RD 1483/2012).

Para llevar a cabo el proceso de consulta y negociación se debe constituir una comisión negociadora en representación de los trabajadores. Ésta actuará en relación a la totalidad de la empresa, o de manera diferenciada por centros de trabajo, si fuera el caso. Las secciones sindicales podrán intervenir como interlocutores cuando así lo acuerden, siempre que sumen la mayoría de los miembros del comité de empresa o entre los delegados de personal. De no hacerlo, o de no existir representación sindical, corresponde a los representantes unitarios (comités de empresa y delegados de personal) del ámbito afectado por la propuesta empresarial. En los casos de ausencia de representación legal, los trabajadores podrán atribuir su representación durante la tramitación del procedimiento a una comisión designada conforme al artículo 41.4 del ET. En cualquier caso, la designación de la comisión negociadora deberá realizarse y comunicarse al empresario en el plazo de cinco días a contar desde el inicio del periodo de consultas, sin que la falta de designación pueda suponer la paralización del procedimiento.

Las partes tienen que establecer un calendario de reuniones. Al menos deberán señalar dos reuniones en un intervalo no superior a siete días ni inferior a tres, salvo pacto en contrario. Los encuentros se 
iniciarán en un plazo no inferior a un día desde la fecha de la entrega de la comunicación, y se levantará acta en cada uno de ellos, con firma de todos los asistentes. Podrán darse por finalizadas las consultas cuando las partes alcancen un acuerdo, aunque no se hubiera agotado el plazo de consulta. La firma de un acuerdo entre las partes genera una presunción de concurrencia de las causas justificativas alegadas por el empresario. No obstante, podrán ser impugnadas por existencia de fraude, coacción o abuso de derecho en su conclusión. El acuerdo vincula a las partes, por lo que la decisión empresarial de suspensión de contratos o reducción de jornada habrá de ajustarse al mismo en tal caso. A falta de acuerdo, el empresario podrá decidir las medidas a adoptar.

Una vez finalizado el periodo de consultas, el empresario comunicará a la autoridad laboral competente el resultado del mismo, trasladando copia íntegra del acuerdo alcanzado. Asimismo, el empresario habrá de comunicar a la representación legal de los trabajadores y a la autoridad laboral su decisión sobre la suspensión de contratos o reducción de jornada, acompañando las actas de las reuniones celebradas. La comunicación deberá contemplar un calendario que incluya los días concretos de suspensión de contratos o reducción de jornada individualizados para cada uno de los trabajadores afectados.

Tras la comunicación de su decisión a los representantes y a la autoridad laboral, el empresario podrá proceder ya a notificar individualmente a los trabajadores afectados la medida finalmente adoptada. Esta surtirá efectos desde la fecha de comunicación a la autoridad laboral, salvo que se contemple una posterior. La notificación individual a cada trabajador contemplará los días concretos en que se desarrollará la medida y, en su caso, el horario de trabajo afectado por la reducción de jornada durante todo el periodo que extienda su vigencia.

Así pues, la autoridad laboral ya no ostenta un papel de predominio en el procedimiento y sus funciones quedan reducidas a velar por la efectividad del periodo de consultas, pudiendo remitir, en su caso, advertencias y recomendaciones a las partes que no supondrán, en ningún caso, la paralización ni la suspensión del procedimiento. Igualmente, la autoridad laboral se convierte en una suerte de asesoría legal para los representantes de los trabajadores, ya que éstos podrán remitir a la misma las observaciones y/o cuestiones que estimen oportunas; y ésta, a su vez, podrá remitir advertencias o consejos a la representación de los trabajadores. 


\subsection{Efectos del procedimiento}

La duración de las medidas de suspensión habrá de ajustarse a la situación coyuntural de la empresa, en el sentido de que no deberá extenderse más allá del momento en que esta recupere su situación ordinaria.

Durante la suspensión de los contratos, los trabajadores no tienen derecho a salario ni a indemnizaciones, pero pueden acceder a las prestaciones de desempleo si reúnen las condiciones legalmente exigidas para ello (artículo 208.1.2 de la Ley General de la Seguridad Social). A tales efectos la autoridad laboral debe comunicar a la entidad gestora la decisión empresarial de suspensión, haciendo constar la causa, los trabajadores afectados y el tiempo de suspensión. A petición de la entidad gestora de la prestación por desempleo, la autoridad laboral puede impugnar el acuerdo de suspensión que eventualmente se hubiera alcanzado entre el empresario y los representantes de los trabajadores, si entendiera que su finalidad no es otra que la obtención indebida de las prestaciones por parte de los trabajadores afectados, por inexistencia de la causa motivadora de la situación legal de desempleo (artículo 47 del ET). La empresa deberá comunicar a la entidad gestora las variaciones que se produzcan en el calendario inicialmente previsto para cada uno de los trabajadores afectados al aplicar la suspensión de los contratos o la reducción de jornada.

Por último, la decisión empresarial puede ser objeto de impugnación judicial. En este sentido, la resolución judicial puede declarar la decisión empresarial como justificada o injustificada, pero también nula.

\subsection{Incentivos económicos}

Además de los cambios en el procedimiento que se acaban de mencionar, en los últimos años también se han producido modificaciones en los incentivos económicos diseñados para favorecer la adopción por parte de empresas y trabajadores de EREs de suspensión de contratos o reducción de jornada con el objetivo de garantizar la continuidad del tejido productivo y el mantenimiento de los puestos de trabajo. En particular, el cambio más relevante se produce con el Real Decreto Ley 2/2009, de 6 de marzo, de medidas urgentes para el mantenimiento y el fomento del empleo y la protección de las personas desempleadas, y la Ley 27/2009, de 30 de diciembre, de igual nombre, en los que se adoptan tres medidas relacionadas entre sí: 
- Bonificación de las cuotas empresariales a la Seguridad Social por contingencias comunes de los trabajadores afectados por un ERE de suspensión de contratos o de reducción de jornada. Con el fin de apoyar el mantenimiento del empleo, las cotizaciones de los trabajadores en dicha situación como consecuencia de la aprobación de un ERE se beneficiarán de una bonificación del 50\% La duración de la bonificación será coincidente con la situación de desempleo del trabajador, sin que en ningún caso pueda superar los 240 días por trabajador. Estas bonificaciones serán compatibles con otras ayudas públicas previstas con la misma finalidad, incluidas las reguladas en el Programa de Fomento de Empleo, sin que en ningún caso la suma de las bonificaciones aplicables pueda superar el 100 por 100 de la cuota empresarial a la Seguridad Social. Para beneficiarse de esta medida, la empresa se comprometerá a mantener el empleo de los trabajadores afectados durante por lo menos un año con posterioridad a la finalización de la suspensión de empleo o la reducción de jornada. La medida beneficiaba a las empresas afectadas por EREs de suspensión o reducción presentados entre el 1 de octubre de 2008 y el 31 de diciembre de 2009 (ampliado hasta el 31 de diciembre de 2010 con la Ley 27/2009).

- Reposición de las prestaciones por desempleo a los trabajadores afectados por EREs de suspensión temporal de contratos o de reducción de jornada. A dichos trabajadores se les repondrán las prestaciones por desempleo que hayan consumido en el caso de que posteriormente sean despedidos y pierdan su empleo, o si se ven afectados por una nueva suspensión o reducción derivada de un nuevo ERE. Se pueden dar, por lo tanto, dos supuestos:

- En el caso del despido, sus causas tienen que ser económicas, técnicas, organizativas o de producción, bien como consecuencia de un despido colectivo o por un despido por causas objetivas de acuerdo con el artículo 52.c del ET. La reposición de las prestaciones consumidas durante el primer ERE será, en este caso, de hasta 120 días. Esta medida beneficiaba a los trabajadores afectados por EREs de suspensión o reducción que se hubiesen autorizado entre el 1 de octubre de 2008 y el 31 de diciembre de 2009 (2010) y que hubiesen sido despedidos entre el 8 de marzo de 2009 y el 31 de diciembre de 2011 (2012).

- En el supuesto de que el trabajador, en lugar de perder el empleo, se vea afectado por un nuevo ERE de suspensión de 
empleo o reducción de jornada, la reposición de las prestaciones consumidas se efectuará si al trabajador no le queda periodo suficiente de prestaciones por desempleo, y en este caso la reposición será de hasta 90 días. Esta medida también beneficiaba a los trabajadores afectados por EREs de suspensión o reducción que se hubiesen autorizado entre el 1 de octubre de 2008 y el 31 de diciembre de 2009 (2010) y que hubiesen sido afectados por EREs posteriores autorizados entre el 8 de marzo de 2009 y el 31 de diciembre de 2009 (2010).

- Autorización para que los trabajadores que hayan perdido su empleo como consecuencia de un ERE puedan posteriormente trabajar sin perder los beneficios del ERE. En este caso, con el fin de promover la mejora de las condiciones de los trabajadores que fuesen objeto de planes de prejubilación, se permitía la compatibilidad entre el trabajo y el mantenimiento de los convenios con la Seguridad Social de quienes perdiesen su empleo como consecuencia de un ERE.

Las reformas de 2010 y 2012 mantuvieron estos incentivos, extendiéndolos a EREs presentados hasta el 31 de diciembre de 2011 y el 31 de diciembre de 2013, respectivamente. La reforma de 2010 amplió la bonificación del $50 \%$ de las cuotas empresariales a la Seguridad Social por contingencias comunes comentada anteriormente hasta el $80 \%$, cuando la empresa, en los procedimientos de regulación de empleo que hayan concluido con acuerdo, incluya medidas para reducir sus efectos entre los trabajadores afectados, tales como acciones formativas durante el período de suspensión de contratos o de reducción de jornada cuyo objetivo sea aumentar la polivalencia del trabajador o incrementar su empleabilidad, o cualquier otra medida alternativa o complementaria dirigida a favorecer el mantenimiento del empleo en la empresa. Además, el compromiso de la empresa para mantener el empleo de los trabajadores afectados por los EREs se redujo a seis meses. La reforma de 2012 eliminó dicho incentivo adicional y situó nuevamente en un año el compromiso de mantenimiento de empleo de la empresa. 


\section{Cambios en la regulación de los despidos y la flexibilidad interna}

Los objetivos de las reformas de la normativa laboral de 20102011 y 2012 han sido comunes, centrando sus modificaciones en cuatro aspectos clave de cualquier mercado de trabajo: la contratación, la intermediación laboral y las políticas activas, la negociación colectiva y los despidos. La reforma de 2010-2011 se dirigió a modificar amplios espacios de la normativa laboral existente, mientras que la de 2012 profundizó en algunos aspectos (como la flexibilidad interna de las empresas y la reducción de los costes de despido) ya iniciados en la anterior. ${ }^{7}$ Centrándonos precisamente en estos dos últimos aspectos, veamos cuáles han sido las modificaciones fundamentales introducidas por ambas reformas puesto que, para entender adecuadamente la posible influencia de los cambios que afectan a los EREs de suspensión de contratos y de reducción de jornada, estos deben enmarcarse en las alteraciones más amplias que se han producido en los ámbitos de la regulación de las medidas de flexibilidad interna y de los despidos.

\subsection{Flexibilidad interna}

En cuanto a la flexibilidad interna, la reforma de 2010-2011 profundiza en cuatro ámbitos que ya habían sido tratados en la reforma de 1994 (y en la de 1997) en el sentido de intentar flexibilizar la organización interna de las empresas y permitir una mayor adaptación de las condiciones de trabajo a las alteraciones de las condiciones económicas. Estos ámbitos son los traslados colectivos, la modificación sustancial de las condiciones de trabajo de carácter colectivo, la inaplicación del régimen salarial previsto en los convenios de ámbito superior a la empresa y las medidas de reducción del tiempo de trabajo. Con respecto a los dos primeros, trata de extender los acuerdos entre trabajadores y empresarios al plantear la posibilidad de que incluso en las empresas pequeñas en que no hay representación legal de los trabajadores se pueda formar una comisión sindical para llegar a un acuerdo y, además, que se pueda sustituir el período de consultas por la mediación o el arbitraje en el ámbito de la empresa. Por lo que respecta a la cláusula de descuelgue salarial, se regula de forma más completa

\footnotetext{
7 Una descripción amplia de los distintos puntos de la reforma de 2010 puede encontrarse en Pérez Infante (2010a, 2010b) y en el monográfico de Temas Laborales (2010). Con respecto a la reforma de 2012, puede consultarse Pérez Infante (2012) así como el monográfico de Temas Laborales (2012).
} 
este procedimiento, tratando de facilitarlo mediante el acuerdo entre las partes y, en caso de desacuerdo, apelando a la mediación extrajudicial (los convenios o acuerdos interprofesionales podrán establecer un arbitraje vinculante). Finalmente, como se vio en la sección anterior, también se flexibilizan las condiciones para fomentar la adopción de medidas de reducción del tiempo de trabajo, introduciendo la medida de reducción temporal de jornada en el artículo 47 del ET y ampliando los incentivos para trabajadores y empresarios vinculados a la utilización de esta medida.

Adicionalmente, el Real Decreto Ley 7/2011, de 10 de junio, de medidas urgentes para la reforma de la negociación colectiva, modifica aspectos relacionados con la estructura de la negociación y la concurrencia de convenios colectivos (fija la prioridad aplicativa del convenio de empresa sobre un convenio de ámbito superior -salvo que un convenio autonómico o estatal lo impida- en relación con determinadas materias: salario base y complementos salariales, compensación de horas extraordinarias, horario y distribución del tiempo de trabajo, entre otras), el contenido y la vigencia de los convenios (fijación de un plazo de preaviso para la denuncia del convenio, un plazo para el inicio de las negociaciones del nuevo convenio, un plazo máximo de negociación y el recurso voluntario a los sistemas de solución no judicial de discrepancias como la mediación o el arbitraje) y la definición de los sujetos que han de negociar los convenios (se adapta la regulación a las nuevas realidades empresariales, como los grupos de empresas o las empresas en red).

La reforma de 2012 profundiza aún más en los aspectos que se acaban de mencionar. En lo que respecta a la modificación de las condiciones de trabajo, incluidas las salariales, se diferencia entre las que modifican (inaplicándolas) condiciones de trabajo establecidas en un convenio estatutario (de sector o de empresa) y las que modifican condiciones de trabajo no establecidas en un convenio (sino en contratos, acuerdos o pactos colectivos diferentes de los convenios extraestatutarios) o disfrutados por los trabajadores en virtud de una decisión unilateral del empresario de efectos colectivos:

- En el caso de que las modificaciones no afecten a un convenio colectivo, se podrán realizar unilateralmente por la empresa, con la posibilidad de que en caso de disconformidad el trabajador afectado pueda rescindir el contrato si se considera perjudicado con una indemnización de 20 días de salario por año de servicio (y un máximo de nueve mensualidades). Por otra parte, las causas para realizar las modificaciones simplemente tienen que 
estén relacionadas con la competitividad, la productividad o la organización técnica o de trabajo de la empresa, sin que sea necesario que las modificaciones contribuyan a prever una evolución negativa de la empresa o a mejorar la situación y las perspectivas de la misma, como se exigía en la normativa anterior.

- En el caso de modificación de las condiciones de trabajo establecidas en un convenio colectivo (es decir, en caso de descuelgue o inaplicación de un convenio), además de unificarse la regulación para la inaplicación de los acuerdos salariales y de otras condiciones de trabajo (anteriormente reguladas en artículos diferentes, el artículo 82.3 y el 41.6 del ET, respectivamente), el cambio principal es la notable ampliación de las causas que lo permiten, siguiendo la estela de los despidos objetivos, al ser suficiente con la disminución de los ingresos ordinarios o las ventas durante dos trimestres consecutivos (uno menos que en los despidos).

- Aunque se mantiene la necesidad de alcanzar un acuerdo para que la empresa pueda proceder a la inaplicación del convenio correspondiente, de sector o de empresa, se establece que, en caso de que se mantenga la discrepancia después de someterla a la comisión paritaria del convenio o a los procedimientos establecidos en los correspondientes acuerdos interprofesionales estatales o autonómicos, cualquiera de las partes podrá someter la solución de la discrepancia al arbitraje de la Comisión Consultiva Nacional de Convenios Colectivos o, en su caso, a la correspondiente Comisión de la Comunidad Autónoma. Esto implica, por el carácter tripartito de esas comisiones, la participación de la Administración estatal o autonómica en ese arbitraje, algo que parece que puede afectar a la autonomía de las partes negociadoras de los convenios colectivos.

- En las materias relacionadas con la flexibilidad interna de las empresas se introducen otros cambios importantes, tanto en lo que respecta a la distribución irregular por parte de la empresa de la jornada a lo largo del año (hasta el 10\% de la misma, en vez de hasta el 5\%) como a la movilidad funcional y geográfica de los trabajadores, al facilitar ambos supuestos de movilidad. En este sentido, destaca la generalidad y la extensión de las causas de la movilidad geográfica, al bastar, sin mayor precisión, como en el caso de la modificación de condiciones de trabajo no previstas en convenio colectivo, razones relacionadas con la competitividad, la 
productividad o la organización técnica o de trabajo de la empresa.

\subsection{Despidos}

Por lo que respecta a la extinción de los contratos, la reforma de 2010-2011 trata de facilitar las posibilidades de despido:

- Clarifica las circunstancias en que es posible el despido individual objetivo por causas económicas, técnicas, organizativas y de producción, dando una nueva redacción al artículo 51.1 del ET. Además, incorpora la necesidad de que la empresa acredite la concurrencia de alguna de esas causas así como la justificación razonable de que de dichas causas se deduce la decisión extintiva.

- Con objeto de evitar incertidumbre judicial en los despidos en que se alegan causas económicas, se explicitan dichas causas: la existencia de pérdidas actuales o previstas o la disminución persistente del nivel de ingresos de la empresa, que puedan afectar a su viabilidad o a su capacidad de mantener el volumen de empleo.

- Establece la misma definición de la causa económica tanto para los despidos económicos objetivos como para los despidos colectivos.

- Reduce el plazo de preaviso en caso de despido objetivo de 30 a 15 días.

- Establece que el Fondo de Garantía Salarial (FOGASA) pagará 8 días de la indemnización por despido objetivo (incluidos los improcedentes) de los nuevos contratos indefinidos firmados tras la reforma, siempre que el contrato haya tenido una duración superior a un año.

- Reduce los plazos para la tramitación de los ERE, ya que todos los periodos que antes se consideraban mínimos pasan a ser máximos (en caso de acuerdo el tiempo para que la Administración dé la autorización baja de 15 a 7 días), y hay una nueva redacción que alude al plan social del ERE de una forma más clara como un instrumento para conseguir la recolocación de los despedidos.

La reforma de 2012 sigue la misma línea de flexibilizar el procedimiento de despido y reducir el coste del mismo por diversas vías: 
- Se suprime la posibilidad de reconocimiento por parte del empresario de la improcedencia del despido (el llamado 'despido exprés', introducido por la Ley 45/2002) con la finalidad de potenciar el despido procedente por causas objetivas (con una indemnización establecida por el ET de 20 días de salario por año de servicio, con un máximo de 12 mensualidades).

- Se amplían considerablemente las causas, sobre todo las económicas, que pueden dar lugar a despidos, al bastar con una disminución de los ingresos ordinarios o de las ventas durante tres trimestres consecutivos en relación con los mismos trimestres del año anterior, sin necesidad de que se produzcan pérdidas actuales o futuras.

- En el caso de los despidos colectivos (así como en el caso de las suspensiones temporales de contrato y la reducción de jornada, como se ha visto más arriba) se suprime la necesidad de la autorización administrativa. En este caso, cuando el despido colectivo afecte a más de 50 trabajadores, la empresa debe ofrecer un plan de recolocación externa de los despedidos diseñado para un periodo mínimo de seis meses. Cuando haya trabajadores despedidos de 55 o más años de edad, la empresa deberá abonar las cuotas destinadas a la financiación de un convenio especial con la Seguridad Social. Además, si hay trabajadores despedidos de 50 o más años de edad, la empresa tiene más de 500 trabajadores y ha tenido beneficios en los dos ejercicios anteriores, ésta deberá realizar una aportación económica al Tesoro Público que estará en función del porcentaje de dicho colectivo en relación con el volumen de despedidos, del número de trabajadores de la empresa y del porcentaje de beneficios sobre los ingresos.

- Se suprime el contrato de fomento para la contratación indefinida creado en la reforma de 1997 y conocido por la indemnización por despido improcedente objetivo de 33 días de salario por año de servicio (con un máximo de 24 mensualidades).

- Se reduce la indemnización por despido improcedente del contrato indefinido ordinario de 45 a 33 días de salario por año de servicio, con la rebaja correspondiente del tope máximo de 42 a 24 mensualidades, con un sistema de retroactividad parcial de las nuevas indemnizaciones, al considerarse esas nuevas indemnizaciones para el período de ocupación del trabajador desde el 12 de febrero de 2012 (fecha de la entrada en vigor de 
las nuevas cuantías), aunque el trabajador haya sido contratado antes.

- También en el caso del despido improcedente se suprimen los salarios de tramitación, salvo cuando, caso muy poco frecuente, el trabajador sea readmitido por el empresario.

- Establece que el FOGASA pagará 8 días de la indemnización por despido objetivo (solo los procedentes) en las extinciones realizadas en las empresas de menos de 25 trabajadores (por tanto, se vuelve a la redacción anterior a la reforma de 2010).

\section{El uso de los EREs de suspensión de contratos y reducción de jornada}

Tanto la reforma laboral de 2010-2011 como, sobre todo, la de 2012 se dirigieron a facilitar, mediante la reducción de los costes y la flexibilidad de los procedimientos, los mecanismos de salida del empleo (a través de los despidos individuales y colectivos) a la vez que trataban de facilitar los instrumentos de respuesta interna de las empresas ante cambios en las condiciones económicas (y de otro tipo), facilitando los descuelgues y la modificación unilateral por el empresario de las condiciones de trabajo e incentivando la realización de ajustes temporales mediante la suspensión de contratos y la reducción de jornada. En principio, según los reformadores, esto debería servir para hacer más flexible el mercado de trabajo, contribuir a la creación de empleo y reducir la temporalidad y la segmentación del mercado de trabajo, pues la mayor facilidad de ajuste interno debería favorecer el uso de los contratos indefinidos.

En el caso de los procedimientos de reparto temporal de empleo, los incentivos para los trabajadores pueden calificarse de ambivalentes pues, a la vez que se ofrecían incentivos económicos (mediante la reposición de las prestaciones y el mantenimiento de los beneficios de los EREs en caso de despido y empleo posterior), los cambios en el procedimiento y el periodo de consultas implicaban un menor poder de negociación por parte de sus representantes. Por otro lado, desde la perspectiva de las empresas, los incentivos económicos y las alteraciones del procedimiento (especialmente, la eliminación de la solicitud a -y la autorización de- la autoridad laboral) y de la justificación de las causas (económicas) también estaban pensados para facilitar su adopción, aunque en este caso todo ello se tenga que considerar relativamente a las modificaciones sufridas por el resto de los procedimientos de ajuste disponibles para los empresarios. Desde 
este punto de vista, puede decirse que las dos líneas de actuación emprendidas por ambas reformas laborales iban en dirección contraria, pues la primera se dirigía a facilitar la flexibilidad en el margen extensivo (externa) mientras que la segunda se centraba en el margen intensivo (interna). Esto significa que resulta difícil dilucidar desde la perspectiva de las empresas si resultaba más ventajoso llevar a cabo EREs de suspensión de contratos y reducción de jornada tras las reformas. Veamos qué nos dicen los datos.

Para obtener una idea adecuada de la extensión del uso de los programas de reparto temporal del trabajo y su utilización en relación con los despidos, se ha procedido a calcular la incidencia de cada tipo de EREs para el total de la economía y de forma desagregada por sectores de actividad económica. Dado que las empresas pueden utilizar los despidos individuales y los colectivos para ajustar cuantitativamente sus plantillas, se han considerado solo estos últimos (EREs de extinción), puesto que su estructura institucional es más parecida a las suspensiones y las reducciones de jornada (ambos mecanismos de ajuste requieren la puesta en marcha de un ERE). Además, los cambios legales en el caso de los despidos colectivos se han producido a la vez y son de similar índole a los que han tenido lugar en los EREs de suspensión y reducción.

Para examinar dicha cuestión, se ha relacionado el número de trabajadores afectados por cada tipo de ERE en un año y el número total de trabajadores que potencialmente podrían verse afectados. El segundo se ha aproximado por el volumen anual medio de asalariados según la EPA, mientras que el primero procede de la "Estadística de Regulación de Empleo" publicada por el Ministerio de Empleo y Seguridad Social. Esta información se recoge a través de las fichas estadísticas cumplimentadas mensualmente por la Dirección General de Empleo del Ministerio o las Comunidades Autónomas que tienen transferidas las funciones en esta materia, ofreciendo datos sobre el número total de EREs presentados por las empresas y resueltos por la autoridad laboral competente y sobre el número total de trabajadores afectados. Los datos permiten distinguir según tipo (suspensión de contratos, reducción de jornada y extinción), sector de actividad económica (agricultura, industria, construcción y servicios) y tamaño de la empresa (en categorías, desde 1-9 trabajadores hasta más de 5.000 trabajadores).

Para comenzar, el gráfico 1 muestra la evolución de la tasa de incidencia de los programas de reparto temporal del trabajo con respecto al total de asalariados, distinguiendo entre suspensiones de contratos y reducciones de jornada, y la de los despidos colectivos (EREs de extinción). Pueden mencionarse dos aspectos de especial interés. Primero, el uso de los EREs y, por tanto, de las medidas de flexibilidad tanto interna como 
externa, varía de manera contracíclica: aumenta en periodos de crisis económica y elevados niveles de paro (1979-1985, 1992-1993 y 2008-2013) y disminuye en periodos de expansión y creación neta de empleo (19861991 y 1995-2007). En el caso de los programas de reparto del trabajo, aunque su uso se incrementó sustancialmente al comienzo de la última recesión (desde el $0,2 \%$ en 2007 al $3,1 \%$ en 2009), este aumento es comparativamente pequeño en perspectiva histórica: casi el $9 \%$ de los asalariados se vieron afectados por EREs de suspensión o reducción de jornada en 1985 y el 5\% en $1993 .{ }^{8}$ Algo similar sucede con los despidos colectivos, que llegaron a afectar al 0,6\% de los asalariados en 2012, frente al $1 \%$ en 1985 y el $1,3 \%$ en 1993.

Segundo, las suspensiones de contratos han sido tradicionalmente la principal forma de reparto del trabajo, lo cual es más cierto desde finales de la década de 1980. Parece que la reducción de horas fue una herramienta relevante para ajustarse a los cambios estructurales en las décadas de 1970 y 1980, pero su importancia prácticamente desapareció a partir de la crisis de 1992-1993, aunque durante la última recesión esta forma de ajuste aumentó su peso y llegó a alcanzar a un $0,7 \%$ de los asalariados en 2012. Los despidos colectivos han desempeñado un papel similar, siendo relativamente más importantes hasta mediados de los años 1990; en la última etapa de crisis económica solo han adquirido un peso mayor a medida que la recesión se prolongaba en el tiempo.

Un aspecto que hay que tener en cuenta es que los instrumentos de flexibilidad interna pueden aplicarse más fácilmente en determinadas empresas y sectores de actividad, no solo por la tecnología que emplean o la organización productiva y del trabajo que llevan a cabo sino también por la capacidad de negociación de trabajadores y empresarios. Esto requeriría el uso de información desagregada por ramas de actividad o tamaño de empresa. Los datos de la "Estadística de Regulación de Empleo" permiten cruzar la información por sector y tipo de ERE, así que son los que vamos a utilizar aquí.

\footnotetext{
8 Por lo que respecta a los recursos financieros, las estimaciones disponibles (puesto que no existen datos oficiales) sugieren que el gasto ascendió a casi 600 millones de euros en 2009 y a 1.000 millones en 2012, lo que representa en torno al $0.05 \%$ y el $0.1 \%$ del PIB, respectivamente (véase Arranz et al., 2015). Esta cantidad incluye son solo las prestaciones por desempleo pagadas a los trabajadores en ERE sino también las contribuciones sociales pagadas por el Servicio Público de Empleo a la Seguridad Social.
} 


\section{Gráfico 1: Evolución de la tasa de incidencia de los EREs de suspensión de contratos, de reducción de jornada y de extinción (España, 1977-2014)}

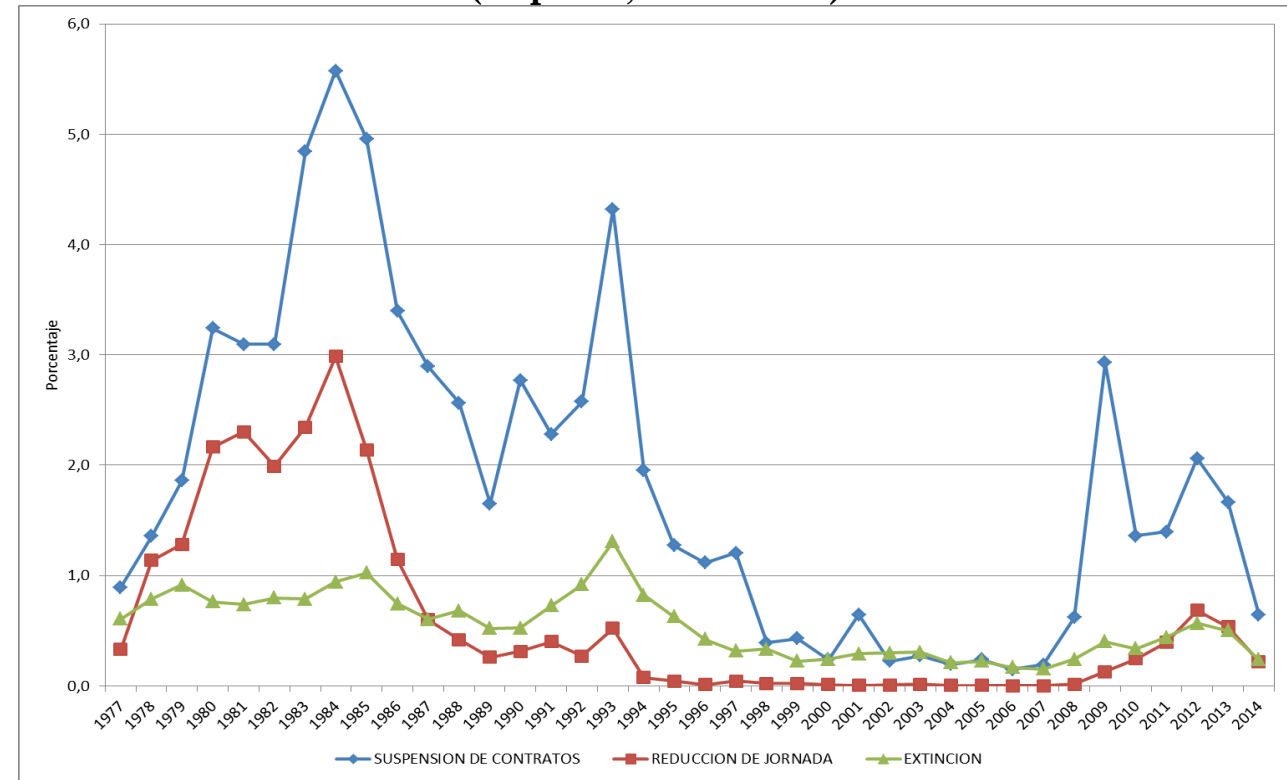

Fuente: Estadística de Regulación de Empleo (Ministerio de Empleo y Seguridad Social) y EPA (INE)

En primer lugar, los gráficos 2 a 5 ofrecen la evolución de las tasas de incidencia por tipo de ERE para cada uno de los sectores (agricultura, industria, construcción y servicios, respectivamente). La industria es el sector en que el uso de programas de reparto de empleo está más extendido y, por tanto, el que determina el comportamiento cíclico de la tasa agregada. ${ }^{9}$ La incidencia estimada en este sector aumentó al comienzo de la década de los 1980, alcanzando un máximo de $23,6 \%$ en 1984 (14,5\% en suspensiones y $9,1 \%$ en reducciones de jornada), no llegando a dichos niveles en los años siguientes debido al escaso uso de la reducción de jornada como forma de ajuste. Sin embargo, la tasa de incidencia de los EREs de suspensión de contratos fue parecida en las dos siguientes crisis, situándose en torno a un 15\% en 1993 y 2009 (cifra similar a la registrada en 1984). Al mismo tiempo,

\footnotetext{
${ }^{9}$ Desde el punto de vista de la distribución, la industria también es la que concentra la mayoría de trabajadores afectados por medidas de reparto del trabajo (más del $70 \%$ a lo largo del periodo considerado, especialmente en el caso de las suspensiones de contratos pero también el de las reducciones de jornada hasta comienzos de la década de los 2000).
} 
los despidos colectivos también han perdido peso en la última recesión con respecto a lo observado en la crisis de principios de los 1990.

En la construcción, el comportamiento de los instrumentos de ajuste responde bastante al ciclo, aumentando su uso cuando las condiciones económicas empeoran; resulta interesante comprobar que el peso de los despidos colectivos es relativamente importante como forma de ajuste en los periodos de crisis, quizás reflejando la mayor sensibilidad cíclica de la producción y del empleo de este sector en comparación con el resto. ${ }^{10}$ Algo similar sucede en los servicios aunque a un nivel más bajo. Por último, en la agricultura el uso de la reducción de jornada ha sido siempre prácticamente nulo y el de los despidos colectivos muy bajo, recayendo el ajuste en las suspensiones de contratos, especialmente hasta mediados de los 1990.

En segundo lugar, es posible llevar a cabo un análisis más pormenorizado de lo que ha sucedido en la última recesión. Desde el punto de vista de la distribución (información no mostrada), las ramas que concentran una parte importante de los trabajadores involucrados en procedimientos de reparto temporal del trabajo son "Fabricación de vehículos de motor, remolques y semirremolques", "Metalurgia; fabricación de productos de hierro, acero y ferroaleaciones" y "Fabricación de productos metálicos, excepto maquinaria y equipo": $25,8 \%$ en 2009 y $12-16 \%$ en $2010-2013$, en el primer caso, $12-15 \%$ en 2009-2011 y 5-6\% en 2013-2014, en el segundo caso, y alrededor del 6\% en todo el periodo, en el tercer caso. Otras ramas industriales (relacionadas con la fabricación de productos metálicos de distinto tipo y de maquinaria y equipo) también son relevantes. Fuera de la industria, solo "Actividades de construcción especializada", "Venta y reparación de vehículos de motor y motocicletas" y "Comercio al por mayor e intermediarios del comercio, excepto de vehículos de motor y motocicletas" acumulan un peso superior al $2 \%$ durante los años recesivos.

10 Esta característica puede estar relacionada en parte con la naturaleza de activo cíclico de los bienes inmuebles (Malpezzi y Wachter, 2005). 


\section{Gráfico 2: Tasa de incidencia de los EREs en la agricultura} (España, 1979-2014)



Fuente: Estadística de Regulación de Empleo (Ministerio de Empleo y Seguridad Social) y EPA (INE).

\section{Gráfico 3: Tasa de incidencia de los EREs en la industria} (España, 1979-2014)

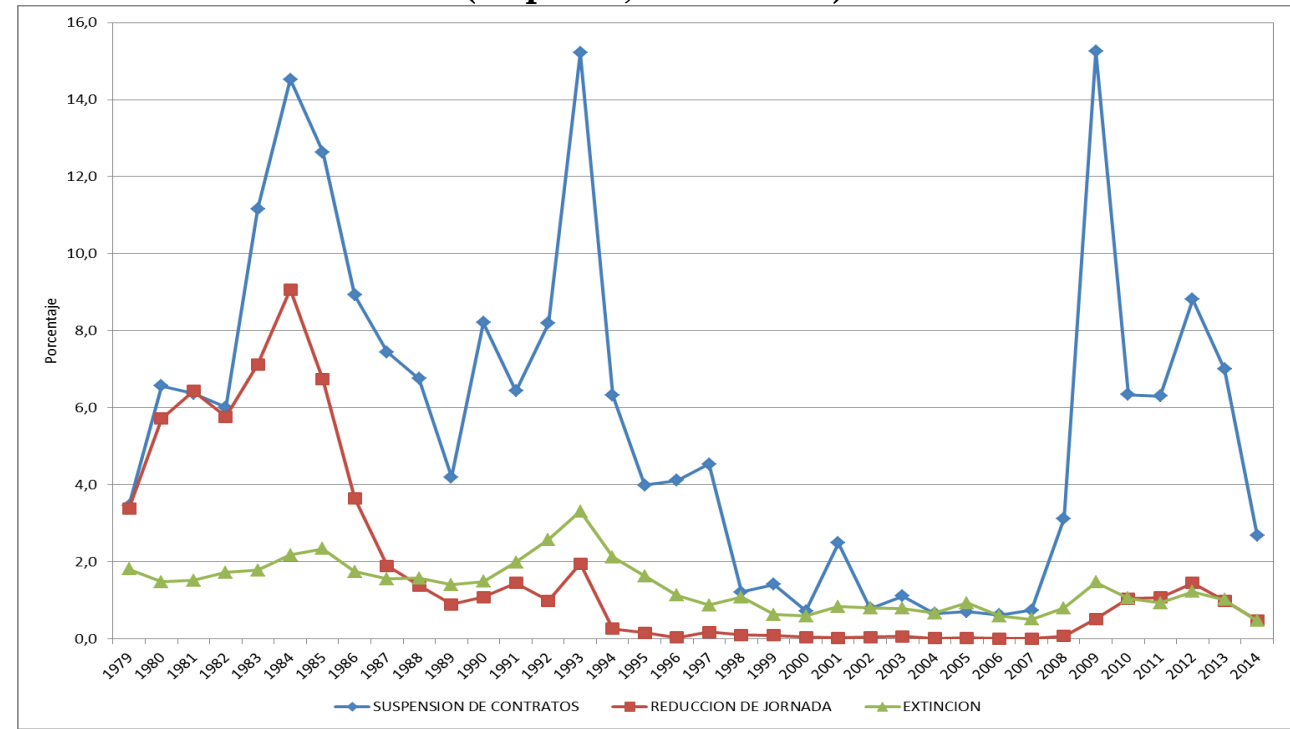

Fuente: Estadística de Regulación de Empleo (Ministerio de Empleo y Seguridad Social) y EPA (INE). 


\section{Gráfico 4: Tasa de incidencia de los EREs en la construcción}

(España, 1979-2014)

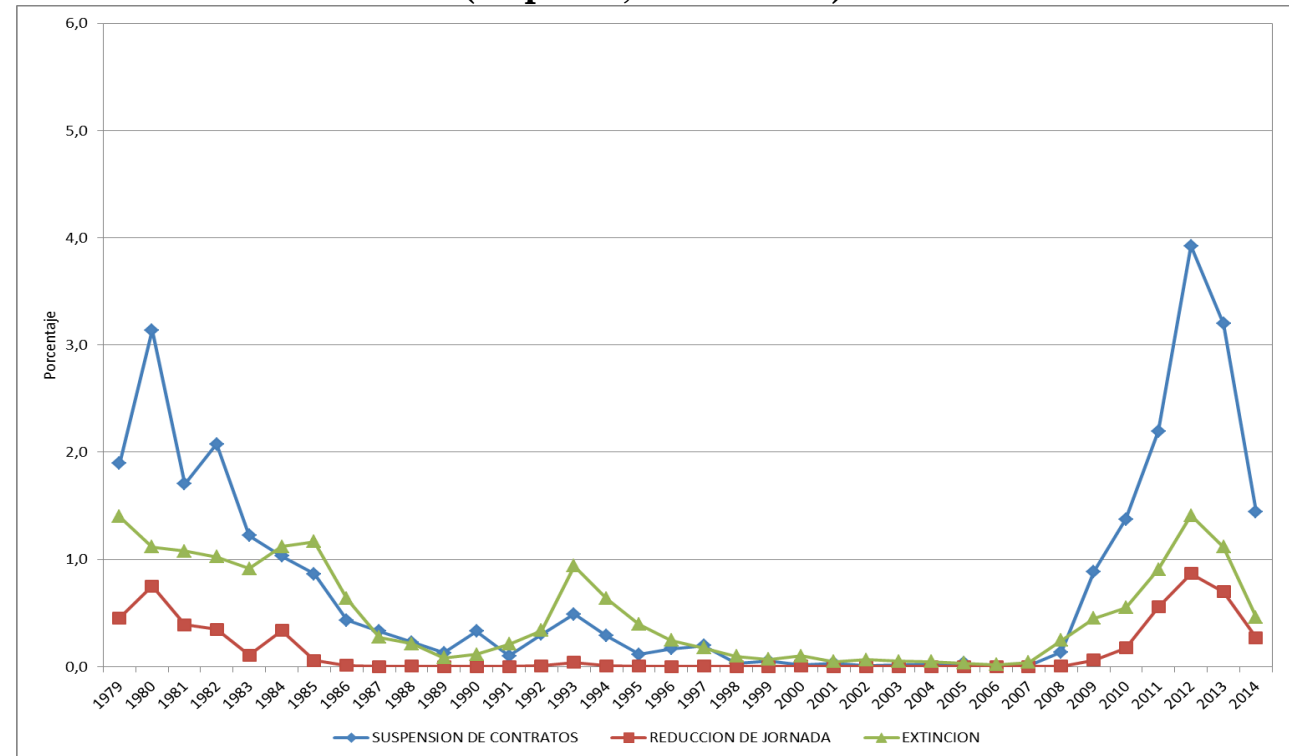

Fuente: Estadística de Regulación de Empleo (Ministerio de Empleo y Seguridad Social) y EPA (INE).

\section{Gráfico 5: Tasa de incidencia de los EREs en los servicios}

(España, 1979-2014)

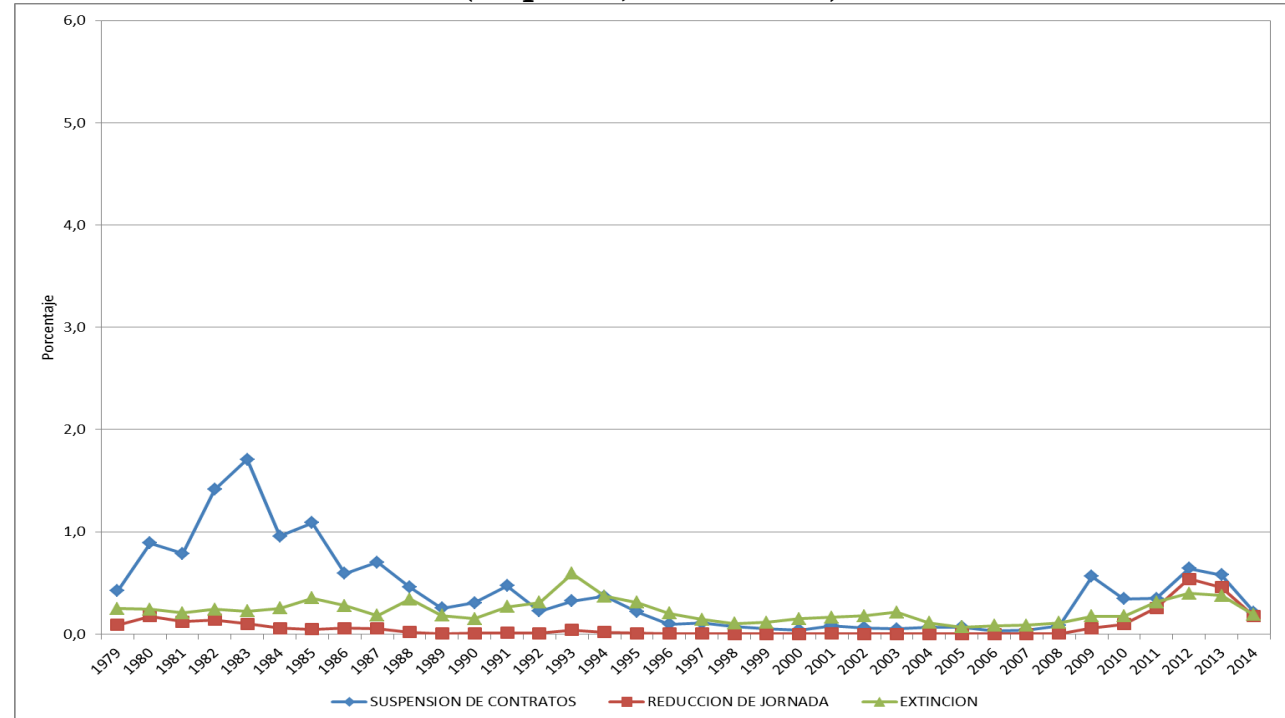

Fuente: Estadística de Regulación de Empleo (Ministerio de Empleo y Seguridad Social) y EPA (INE). 
Centrándonos en la incidencia, el cuadro A1 del Apéndice ofrece las tasas de incidencia de los EREs de suspensión de contratos y reducción de jornada, por una parte, y de extinción, por otra parte, por ramas de actividad económica (CNAE a dos dígitos) para el periodo 2009-2014. Las ramas que presentan las tasas más elevadas son las ramas industriales mencionadas antes (especialmente "Fabricación de vehículos de motor, remolques y semirremolques" y "Metalurgia; fabricación de productos de hierro, acero y ferroaleaciones" y "Fabricación de productos metálicos, excepto maquinaria y equipo"), pero también otras industriales (como "Industria textil") y del sector primario ("Pesca y acuicultura" y "Extracción de antracita, hulla y lignito") y de servicios ("Otras actividades profesionales, científicas y técnicas").

Estas cifras pueden compararse con las tasas de incidencia de los EREs de extinción (despidos colectivos), que también se presentan en dicho cuadro. Puede comprobarse que estas tasas son mucho más bajas $\mathrm{y}$, en general, superiores al 1\% en la mayoría de las ramas industriales, siendo mayores en el periodo 2009-2011 en ciertas ramas como "Fabricación de productos de caucho y plásticos", "Fabricación de otros productos minerales no metálicos" e "Industria textil" (también en "Telecomunicaciones"). Una forma sencilla de comparar ambas tasas de incidencia consiste en dividirlas. Este indicador simple nos dice si es relativamente más importante llevar a cabo procedimientos de flexibilidad interna en comparación con los de flexibilidad externa dentro de cada rama de actividad. Para el agregado, las cifras van de 7,7 veces en 2009 a $4-5$ veces en 2010-2014. Los resultados desagregados (no mostrados) indican que las cifras tienden a ser elevadas precisamente en el conjunto de ramas industriales que se han señalado más arriba, que grosso modo son las de los grupos 22 a 31 de la CNAE, es decir, las que tienen que ver con fabricación de productos metálicos de diverso tipo y con maquinaria, equipo y material de transporte, así como en algunas de servicios (como "Actividades jurídicas y de contabilidad" y "Actividades de las sedes centrales; actividades de consultoría de gestión empresarial"). Todo ello lleva a pensar que ante un empeoramiento de las condiciones económicas las empresas emplean en mayor medida mecanismos de reparto del trabajo (además de la reducción del empleo temporal, que es la forma más sencilla de responder a una caída de la actividad) y más adelante, si la crisis se prolonga, acuden a procedimientos extintivos de los empleos permanentes. 
La principal conclusión de este análisis descriptivo es que el uso de los procedimientos de reparto temporal de empleo está concentrado en algunas ramas del sector industrial, que comprenden actividades relacionadas con la producción de bienes (bienes metálicos, equipo mecánico o eléctrico y fabricación de automóviles), que pueden verse más afectadas por variaciones estacionales de la demanda y cuyas empresas responden con rapidez a estas variaciones alterando el número de horas trabajadas por sus empleados para ajustar la demanda de trabajo (el total de horas) al cambio de la demanda de bienes. ${ }^{11}$ Puede aventurarse que en estas empresas los instrumentos de flexibilidad interna pueden aplicarse más fácilmente porque el proceso productivo y la organización del trabajo son diferentes a los de las empresas de servicios y porque la capacidad de negociación de trabajadores y empresarios es también distinta.

Para terminar, con respecto al posible impacto de los incentivos financieros, tanto la información ofrecida en los gráficos y los cuadros como, sobre todo, la información mensual de los trabajadores afectados (no mostrada) sugieren que las empresas incrementaron el uso de los EREs de suspensión de contratos y reducción de jornada ya antes de la aprobación de las medidas del año 2009 (de hecho, el aumento comienza a ser importante a partir de octubre de 2008 y alcanza máximos locales en febrero, julio y diciembre de 2009). Pero lo más relevante no es si dichos mecanismos se emplearon más sino si fueron eficaces para cumplir su objetivo de preservar los puestos de trabajo y mantener a los trabajadores ocupados en las mismas empresas.

En el caso español, no existen estudios que se hayan planteado esta cuestión, salvo Arranz et al. (2015). Estos autores utilizan una metodología de diferencias-en-diferencias para identificar el efecto de participar en un ERE de suspensión de contrato o reducción de jornada sobre la probabilidad de que un trabajador siga ocupado en la misma empresa uno, dos y tres años después tras la aprobación de los incentivos económicos de marzo de 2009 en comparación con no haber participado en un ERE de dicho tipo y en comparación con el periodo anterior al cambio de los incentivos. En concreto, se comparan trabajadores que participaron en un ERE en el segundo trimestre de 2009 con aquellos que participaron en el cuarto trimestre de 2008 (este sería el grupo de los tratados) y trabajadores que estaban ocupados en las mismas empresas que los anteriores pero no fueron elegidos para participar en un ERE en el

\footnotetext{
11 Esto no es muy diferente de lo que ocurre en otros países, como Alemania o Francia, en que la industria concentra la mayor parte de los procedimientos de reparto temporal de empleo (Calavrezo y Lodin, 2012; Crimmann et al.; 2012).
} 
segundo trimestre de 2009 con aquellos que estaban ocupados en las mismas condiciones en el cuarto trimestre de 2008 (este sería el grupo de control). Los resultados indican que la participación reduce la probabilidad de seguir ocupado en la misma empresa en el futuro tanto antes como después de los cambios en los incentivos económicos y, además, el impacto de éstos ha sido nulo, lo que apuntaría a la existencia de un elevado peso muerto. ${ }^{12}$

Estos resultados se encuentran en línea con lo encontrado por la literatura empírica desarrollada en los últimos años, centrada en realizar comparaciones entre países europeos y de la OCDE a lo largo de varios años. Aunque el efecto de los programas de reparto del trabajo que se encuentra en las estimaciones suele ser positivo (Arpaia et al., 2010), también es cierto que el número de puestos preservados es sustancialmente menor que el volumen de trabajadores equivalentes a tiempo completo implicados, por lo que los costes de peso muerto son potencialmente elevados. Así, Boeri y Brucker (2011) encuentran que para algunos países dicha diferencia implicaría un peso muerto cercano al $100 \%$, aunque la media se sitúa en el 66\%, mientras que Hizjen y Martin (2013) obtienen que, aunque estos programas tuvieron un impacto significativo para proteger el empleo al comienzo de la crisis (el $2 \%$ en Alemania y casi el 1\% en Japón e Italia), su uso continuado en los años siguientes tuvo una influencia negativa sobre el contenido de empleo de la recuperación, por lo que el efecto neto se ha reducido y en algunos países (como los mencionados antes) se ha hecho negativo. Otros trabajos tampoco encuentran un efecto positivo de este tipo de programas sobre el empleo (Bellman et al., 2012).

\section{Conclusiones}

El objetivo de este artículo ha sido presentar las principales modificaciones normativas adoptadas en las últimas reformas laborales

\footnotetext{
12 Osuna y García Pérez (2015) utilizan un modelo de búsqueda de empleo en equilibrio adaptado a la estructura dual del mercado de trabajo español y calibrado para captar el equilibrio estacionario en el que estaba la economía española antes de la reforma de 2012 para evaluar el impacto de las medidas de flexibilidad externa e interna (suspensiones de contrato o reducciones de jornada) adoptadas en dicha reforma sobre la tasa de paro de equilibrio, la tasa de destrucción de empleo y la distribución de la antigüedad. La principal conclusión es que la tasa de paro de equilibrio se reduciría como consecuencia de la reducción de los costes de despido, pero las medidas de flexibilidad interna solo tendrían impacto si las empresas recibiesen una bonificación en la cotización a la Seguridad Social de los trabajadores afectados, tal como sucedió tras la aprobación de los incentivos económicos de marzo de 2009.
} 
en relación con el procedimiento y con los incentivos económicos para la adopción de medidas de reparto temporal del trabajo, es decir, vinculadas a EREs de suspensión de contratos y de reducción de jornada, como alternativa a los despidos a la hora de realizar ajustes en la utilización del factor trabajo.

Para entender adecuadamente su posible influencia, estas modificaciones se han enmarcado en los cambios más amplios que se han producido en los ámbitos de la regulación de las medidas de flexibilidad interna de las empresas (condiciones de trabajo, movilidad geográfica y funcional, etc.) y de los despidos. Tanto la reforma laboral de 2010 como, sobre todo, la de 2012, modificaron de manera sustancial el modelo laboral español, especialmente en lo que se refiere a la legislación de protección del empleo, facilitando, mediante la reducción de los costes y la flexibilidad de los procedimientos, los mecanismos de salida del empleo (a través de los despidos individuales y colectivos), pero también en lo referente a las medidas para permitir la flexibilidad interna, facilitando los descuelgues y la modificación unilateral por el empresario de las condiciones de trabajo. Ambas líneas de actuación han ido en direcciones opuestas, pues la primera se dirigía a facilitar la flexibilidad en el margen extensivo (externa) mientras que la segunda se centraba en el margen intensivo (interna). El resultado de estos cambios no parece claro. Aunque algunos estudios achacan a la reforma de 2012 un impacto positivo sobre variables como el empleo o la tasa de paro (BBVA, 2013) y algunos flujos laborales como la tasa de contratación, las transiciones desde el paro hacia la ocupación o las salidas del empleo temporal (OCDE, 2013), otros no encuentran tal evidencia (Izquierdo et al., 2013).

En el caso de las medidas que incrementaron los incentivos a la adopción de EREs de suspensión de contratos y reducción de jornada a partir de marzo de 2009 y de los cambios en el procedimiento adoptados en las reformas de 2010 y 2012, es difícil separar su efecto del relacionado con la crisis. Si se centra la atención en la industria, que concentra la mayor parte de los trabajadores afectados, la incidencia de estos EREs aumentó rápidamente en 2008 y, sobre todo, 2009, y fue similar a las registrada en las crisis anteriores. Al mismo tiempo, los despidos colectivos también han perdido peso en la última recesión con respecto a lo observado en la crisis de principios de los 1990. Todo ello podría indicar que los incentivos dirigidos a trabajadores y, sobre todo, empresas, ha llevado a un mayor uso relativo de los programas de reparto temporal de trabajo frente a los procedimientos colectivos de extinción para hacer frente a la caída de la actividad producida en a la última recesión. En cuanto a su posible impacto sobre la permanencia 
en el empleo de los trabajadores, no parece que haya sido significativo (Arranz et al., 2015), lo que implicaría un elevado peso muerto de la medida, tal como diversos estudios empíricos que han analizado la influencia de este tipo de programas sobre el empleo han encontrado para otros países (Boeri y Brucker, 2011; Bellman et al., 2012; Hizjen y Martin, 2013).

\section{Bibliografía}

Arranz, J.M.; García-Serrano, C. y Hernanz, V. (2015), Evaluación del impacto de políticas públicas: las prestaciones por desempleo y los expedientes de regulación de empleo, Instituto de Estudios Fiscales, Madrid.

Arpaia, A.; Curci, N.; Mejermans, E.; Peschner, J. y Pierini, F. (2010), "Short time working arrangements as response to cyclical fluctuations", European Economy Occasional Paper, $N^{\circ}$ 64, European Commission.

BBVA (2013), Situación España, Segundo trimestre 2013, BBVA Research, Madrid.

Bellman, L., Gerner, H. y Upward, R. (2012), "The response of German establishments to the 2008-2009 economic crisis", OECD Social, Employment and Migration Working Papers, $N^{\circ}$ 137, OECD Publishing.

Boeri, T. y Bruecker, H. (2011), "Short-time work benefits revisited: some lessons from the Great Recession", Economic Policy, 26(68), 697765 .

Brenke, K.; Rinne, U. y Zimmermann, K.F. (2013), "Desempleo parcial: la respuesta alemana a la Gran Recesión”, Revista Internacional del Trabajo, 132(2), 325-344.

Calavrezo, O. y Lodin, F. (2012), "Short-time working agreements in France during the crisis: an empirical analysis of firms and employees", Comparative Economic Studies, 54, 299-320.

Crimmann, A., Wiesner, F. y Bellman, L. (2012), "Resisting the crisis: short-time work in Germany", International Journal of Manpower, 33(8), 877-900. 
Del Rey, S. (2010), "Las medidas sobre flexibilidad interna en la Ley 35/2010. Una aproximación inicial”, Temas Laborales, 107, 163-191.

Garrido Pérez, E. (2012), "La suspensión del contrato y la reducción de la jornada por causas empresariales", Temas Laborales, 115, 249-273.

Hijzen, A. y Martin, S. (2013), "The role of short-time work schemes during the global financial crisis and early recovery: a cross-country analysis", IZA Journal of Labor Policy, 2(5), 1-31.

Izquierdo, M.; Lacuesta, A. y Puente, S. (2013), "La reforma laboral de 2012: un primer análisis de algunos de sus efectos", Boletín Económico, Banco de España, septiembre, 55-64.

Malpezzi, S. y Wachter, S. (2005), "The role of speculation in real estate cycles", Journal of Real Estate Literature, 13, 143-166.

OCDE (2103), The 2012 labour market reform in Spain: a preliminary assessment, OECD Publishing, París.

Osuna, V. y García Pérez, J.I. (2015), "On the effectiveness of short-time work schemes in dual labor markets", Estudios de Economía Española, 2015/06, FEDEA.

Pérez Infante, J.I. (2010a), "El mercado de trabajo español y la última reforma laboral”, Boletín de Inflación y Análisis Macroeconómico, Instituto Flores de Lemus de la Universidad Carlos III de Madrid, 190 (julio), 69-77.

Pérez Infante, J.I. (2010b), "La reforma laboral después de la Ley 35/2010", Boletín de Inflación y Análisis Macroeconómico, Instituto Flores de Lemus de la Universidad Carlos III de Madrid, 194 (noviembre), 69-83.

Pérez Infante, J.I. (2012), "La última reforma laboral después de la aprobación de la Ley 3/2012, de 6 de julio", artículo incluido en la Tribuna Abierta de la Asociación Española de Economía del Trabajo (www.aeet.es).

Temas Laborales (2010), Monográfico sobre la Reforma Laboral de 2010, 107. 
Temas Laborales (2012), Monográfico sobre la Reforma Laboral de 2012,115 .

\section{APÉNDICE}

Tabla A1: Tasa de incidencia de los EREs de suspensión/reducción y de extinción, según ramas de actividad económica (España, 20092014).

\begin{tabular}{|c|c|c|c|c|c|c|c|c|c|c|c|c|}
\hline & \multicolumn{5}{|c|}{$\begin{array}{r}\text { Incidencia EREs de } \\
\text { suspensión y }\end{array}$} & \multicolumn{7}{|c|}{ Incidencia EREs de extinción } \\
\hline & 2009 & 201 & 201 & 201 & 201 & 201 & 2009 & 201 & 201 & 201 & 201 & 2014 \\
\hline $\begin{array}{l}1 \text { Agricultura, ganadería, caza y servicios } \\
\text { elacionados con las mismas }\end{array}$ & 0,0 & 0,1 & 0,1 & 0,3 & 0,2 & 0,1 & 0,1 & 0,2 & 0,2 & 0,1 & 0,1 & 0,1 \\
\hline 2 Silvicultura y explotación forestal & 0,5 & 0,1 & 0,3 & 1,4 & 1,2 & 0,6 & 0,0 & 0,0 & 0,0 & 0,1 & 0,9 & 0,3 \\
\hline 3 Pesca y acuicultura & 25,6 & 18,6 & 18,3 & 7,7 & 3,9 & 5,6 & 0,3 & 0,9 & 0,7 & 0,3 & 0,5 & 0,2 \\
\hline 55 Extracción de antracita, hulla y lignito & 1,3 & 27,6 & 19,4 & 13,1 & 32,3 & 15,2 & 5,8 & 5,2 & 7,3 & 5,8 & 13,2 & 3,6 \\
\hline $\begin{array}{l}66 \text { Extracción de crudo de petróleo y gas } \\
\text { natural }\end{array}$ & 0,3 & 0,5 & 0,0 & 1,5 & 0,0 & 0,0 & 0,0 & 0,0 & 0,0 & 0,0 & 0,0 & 0,0 \\
\hline 7 Extracción de minerales metálicos & 6,9 & 0,0 & 5,6 & 5,9 & 1,3 & 0,0 & 0,0 & 0,3 & 0,4 & 0,8 & 1,3 & 0,0 \\
\hline 8 Otras industrias extractivas & 3,9 & 6,1 & 6,2 & 13,9 & 9,2 & 3,4 & 1,5 & 0,5 & 0,5 & 1,6 & 2,9 & 0,1 \\
\hline $\begin{array}{l}9 \text { Actividades de apoyo a las industrias } \\
\text { extractivas }\end{array}$ & 6,5 & 12,7 & 4,4 & 15,6 & 0,6 & 0,4 & 0,0 & 1,5 & 9,6 & 0,6 & 0,0 & 1,2 \\
\hline 10 Industria de la alimentación & 0,9 & 1,1 & 1,3 & 1,3 & 1,9 & 1,1 & 0,4 & 0,4 & 0,4 & 0,6 & 0,6 & 0,2 \\
\hline 11 Fabricación de bebidas & 0,9 & 0,5 & 0,5 & 1,4 & 1,4 & 0,6 & 0,6 & 0,7 & 0,7 & 0,3 & 0,0 & 1,0 \\
\hline 12 Industria del tabaco & 0,6 & 0,6 & 0,2 & 0,6 & 0,0 & 0,0 & 13,3 & 3,7 & 1,9 & 0,3 & 0,0 & 0,0 \\
\hline 13 Industria textil & 20,2 & 7,3 & 8,3 & 11,6 & 13,1 & 4,9 & 4,4 & 2,1 & 3,0 & 1,9 & 1,9 & 1,0 \\
\hline 14 Confección de prendas de vestir & 6,8 & 3,4 & 3,0 & 5,3 & 5,4 & 1,6 & 1,9 & 2,4 & 0,6 & 1,0 & 1,9 & 0,8 \\
\hline 15 Industria del cuero y del calzado & 8,0 & 3,5 & 2,5 & 3,7 & 3,2 & 1,1 & 1,8 & 0,6 & 0,4 & 0,5 & 1,0 & 0,3 \\
\hline $\begin{array}{l}16 \text { Industria de la madera y del corcho, excep. } \\
\text { nuebles; cestería }\end{array}$ & 9,9 & 9,8 & 11,8 & 14,6 & 11,3 & 5,0 & 1,9 & 0,9 & 1,9 & 1,6 & 1,2 & 0,6 \\
\hline 17 Industria del papel & 10,8 & 6,7 & 6,1 & 4,4 & 5,5 & 3,8 & 1,6 & 0,5 & 1,0 & 0,5 & 1,6 & 1,4 \\
\hline $\begin{array}{l}18 \text { Artes gráficas y reproducción de soportes } \\
\text { rabados }\end{array}$ & 6,7 & 4,9 & 5,3 & 10,2 & 6,1 & 2,8 & 1,0 & 1,0 & 0,8 & 1,9 & 1,1 & 0,9 \\
\hline 19 Coquerías y refino de petróleo & 0,6 & 0,1 & 0,0 & 0,2 & 0,1 & 0,0 & 0,0 & 0,2 & 0,2 & 0,0 & 0,0 & 0,8 \\
\hline 20 Industria química & 8,5 & 2,4 & 3,0 & 5,4 & 2,3 & 0,7 & 1,3 & 0,6 & 1,0 & 1,0 & 0,5 & 0,2 \\
\hline 21 Fabricación de productos farmacéuticos & 0,8 & 0,4 & 0,6 & 1,3 & 0,8 & 0,3 & 0,8 & 1,5 & 1,0 & 0,6 & 0,4 & 0,4 \\
\hline
\end{tabular}




\begin{tabular}{|c|c|c|c|c|c|c|c|c|c|c|c|c|}
\hline $\begin{array}{l}22 \text { Fabricación de productos de caucho y } \\
\text { plásticos }\end{array}$ & 22,4 & 6,7 & 11,2 & 40,4 & 8,8 & 3,7 & 2,7 & 1,6 & 1,1 & 1,9 & 0,9 & 0,6 \\
\hline $\begin{array}{l}23 \text { Fabricación de otros productos minerales no } \\
\text { metálicos }\end{array}$ & 16,5 & 11,8 & 12,0 & 15,9 & 15,3 & 10,4 & 3,2 & 1,9 & 1,4 & 4,9 & 2,8 & 1,1 \\
\hline $\begin{array}{l}24 \text { Metalurgia; fabricación de productos de } \\
\text { hierro, acero y ferroaleaciones }\end{array}$ & 71,7 & 41,0 & 40,2 & 30,0 & 26,1 & 8,5 & 1,8 & 1,4 & 1,1 & 2,1 & 1,5 & 0,5 \\
\hline $\begin{array}{l}25 \text { Fabricación de productos metálicos, excepto } \\
\text { maquinaria y equipo }\end{array}$ & 17,7 & 9,2 & 7,0 & 13,0 & 10,1 & 4,9 & 1,3 & 1,0 & 1,1 & 1,4 & 1,6 & 0,6 \\
\hline $\begin{array}{l}26 \text { Fabricación de productos informáticos, } \\
\text { electrónicos y ópticos }\end{array}$ & 10,5 & 6,5 & 4,1 & 12,4 & 5,5 & 2,1 & 2,7 & 0,8 & 0,7 & 2,2 & 1,2 & 0,4 \\
\hline 27 Fabricación de material y equipo eléctrico & 17,0 & 8,6 & 10,2 & 18,0 & 4,6 & 3,6 & 2,0 & 1,1 & 0,7 & 1,5 & 0,8 & 0,7 \\
\hline 28 Fabricación de maquinaria y equipo n.c.o.p. & 19,7 & 10,2 & 5,4 & 9,1 & 6,9 & 4,0 & 1,6 & 1,3 & 1,4 & 1,1 & 0,6 & 0,5 \\
\hline $\begin{array}{l}29 \text { Fabricación de vehículos de motor, } \\
\text { remolques y semirremolques }\end{array}$ & 63,0 & 16,1 & 19,1 & 25,9 & 26,4 & 5,3 & 2,5 & 1,9 & 1,0 & 0,5 & 0,8 & 0,3 \\
\hline 30 Fabricación de otro material de transporte & 9,7 & 5,1 & 4,0 & 4,6 & 4,4 & 5,2 & 0,4 & 0,8 & 0,9 & 1,2 & 0,6 & 0,3 \\
\hline 31 Fabricación de muebles & 11,5 & 11,1 & 12,8 & 16,5 & 13,9 & 5,5 & 1,4 & 1,2 & 1,7 & 2,5 & 1,8 & 1,1 \\
\hline 32 Otras industrias manufactureras & 8,5 & 6,4 & 8,4 & 5,5 & 2,5 & 1,5 & 1,3 & 0,8 & 1,1 & 1,0 & 0,4 & 0,4 \\
\hline $\begin{array}{l}33 \text { Reparación e instalación de maquinaria y } \\
\text { equipo }\end{array}$ & 6,6 & 3,1 & 3,2 & 3,4 & 2,1 & 2,1 & 0,8 & 0,7 & 0,4 & 1,1 & 0,8 & 0,2 \\
\hline $\begin{array}{l}35 \text { Suministro de energía eléctrica, gas, vapor y } \\
\text { aire acondicionado }\end{array}$ & 0,4 & 0,3 & 1,4 & 1,0 & 1,2 & 0,1 & 0,5 & 1,4 & 1,0 & 1,1 & 1,3 & 0,3 \\
\hline $\begin{array}{l}36 \text { Captación, depuración y distribución de } \\
\text { agua }\end{array}$ & 0,7 & 0,5 & 0,7 & 0,8 & 0,1 & 0,1 & 0,4 & 0,2 & 0,1 & 0,1 & 0,3 & 0,1 \\
\hline 37 Recogida y tratamiento de aguas residuales & 0,3 & 1,1 & 0,3 & 0,7 & 0,1 & 0,4 & 0,1 & 0,0 & 0,3 & 0,4 & 0,0 & 1,3 \\
\hline $\begin{array}{l}38 \text { Recogida, tratamiento y eliminación de } \\
\text { residuos; valorización }\end{array}$ & 0,4 & 0,6 & 0,6 & 2,0 & 6,1 & 1,1 & 0,1 & 0,2 & 0,0 & 0,7 & 0,5 & 0,1 \\
\hline $\begin{array}{l}39 \text { Actividades de descontaminación y otros } \\
\text { serv. de gestión de residuos }\end{array}$ & 0,0 & 0,2 & 0,8 & 0,9 & 0,0 & 0,0 & 0,0 & 0,1 & 0,0 & 0,4 & 0,0 & 0,0 \\
\hline 41 Construcción de edificios & 0,6 & 1,3 & 2,5 & 4,3 & 3,2 & 1,6 & 0,4 & 0,5 & 1,1 & 1,5 & 1,2 & 0,3 \\
\hline 42 Ingeniería civil & 0,9 & 0,7 & 1,5 & 3,5 & 2,0 & 0,9 & 0,1 & 0,3 & 0,6 & 1,0 & 0,3 & 0,2 \\
\hline 43 Actividades de construcción especializada & 1,5 & 2,1 & 3,4 & 5,8 & 5,1 & 2,0 & 0,6 & 0,6 & 0,9 & 1,5 & 1,4 & 0,6 \\
\hline $\begin{array}{l}45 \text { Venta y reparación de vehículos de motor y } \\
\text { motocicletas }\end{array}$ & 4,4 & 1,3 & 2,4 & 5,1 & 4,2 & 1,2 & 0,3 & 0,3 & 0,6 & 0,8 & 0,9 & 0,3 \\
\hline $\begin{array}{l}46 \text { Comercio por mayor e intermediarios de } \\
\text { comercio, excep. vehículos motor }\end{array}$ & 2,4 & 1,4 & 1,6 & 3,7 & 2,3 & 0,9 & 0,7 & 0,4 & 0,6 & 1,0 & 0,7 & 0,3 \\
\hline $\begin{array}{l}47 \text { Comercio al por menor, excepto de vehículos } \\
\text { de motor y motocicletas }\end{array}$ & 0,3 & 0,3 & 0,4 & 0,8 & 0,6 & 0,3 & 0,2 & 0,1 & 0,2 & 0,2 & 0,3 & 0,2 \\
\hline 49 Transporte terrestre y por tubería & 1,1 & 0,8 & 0,9 & 2,0 & 1,4 & 0,4 & 0,5 & 0,3 & 0,2 & 0,5 & 0,3 & 0,5 \\
\hline $\begin{array}{l}50 \text { Transporte marítimo y por vías navegables } \\
\text { interiores }\end{array}$ & 1,3 & 1,2 & 1,2 & 3,1 & 0,6 & 0,4 & 0,2 & 0,4 & 0,5 & 1,8 & 0,9 & 0,3 \\
\hline 51 Transporte aéreo & 0,2 & 1,3 & 0,3 & 7,3 & 3,7 & 0,0 & 1,6 & 1,2 & 1,0 & 2,6 & 4,6 & 1,9 \\
\hline $\begin{array}{l}52 \text { Almacenamiento y actividades anexas al } \\
\text { transporte }\end{array}$ & 5,0 & 2,9 & 2,0 & 3,8 & 2,9 & 1,3 & 0,8 & 1,2 & 0,6 & 0,8 & 1,0 & 0,4 \\
\hline
\end{tabular}




\begin{tabular}{|c|c|c|c|c|c|c|c|c|c|c|c|c|}
\hline 53 Actividades postales y de correos & 0,0 & 0,3 & 2,7 & 3,2 & 0,3 & 0,2 & 0,1 & 0,1 & 0,0 & 0,1 & 0,2 & 0,4 \\
\hline 55 Servicios de alojamiento & 1,3 & 1,2 & 1,2 & 1,6 & 2,0 & 0,8 & 0,1 & 0,3 & 0,2 & 0,3 & 0,5 & 0,2 \\
\hline 56 Servicios de comidas y bebidas & 0,4 & 0,3 & 0,3 & 0,8 & 0,7 & 0,2 & 0,1 & 0,1 & 0,2 & 0,1 & 0,2 & 0,1 \\
\hline 58 Edición & 0,9 & 1,1 & 1,8 & 2,7 & 3,2 & 2,3 & 1,7 & 0,4 & 0,8 & 1,5 & 2,8 & 0,9 \\
\hline $\begin{array}{l}59 \text { Act. cinematográficas, vídeo y program. } \\
\text { televisión, grabación de sonido }\end{array}$ & 0,2 & 0,8 & 1,0 & 1,5 & 0,9 & 0,4 & 0,1 & 0,3 & 1,8 & 1,6 & 1,2 & 0,6 \\
\hline $\begin{array}{l}60 \text { Actividades de programación y emisión de } \\
\text { radio y televisión }\end{array}$ & 0,3 & 1,5 & 0,4 & 0,9 & 2,6 & 0,2 & 0,1 & 0,2 & 1,1 & 5,6 & 4,1 & 4,1 \\
\hline 61 Telecomunicaciones & 0,2 & 0,1 & 0,3 & 0,6 & 0,3 & 0,1 & 1,4 & 0,3 & 2,8 & 2,4 & 3,0 & 0,1 \\
\hline $\begin{array}{l}62 \text { Programación, consultoría y otras act. } \\
\text { relacionadas con la informática }\end{array}$ & 0,5 & 1,1 & 0,8 & 1,2 & 0,9 & 0,3 & 0,1 & 0,4 & 0,4 & 0,5 & 0,8 & 0,3 \\
\hline 63 Servicios de información & 1,8 & 0,5 & 1,9 & 4,0 & 1,8 & 0,2 & 0,0 & 0,6 & 0,5 & 1,7 & 0,7 & 0,1 \\
\hline $\begin{array}{l}64 \text { Servicios financieros, excepto seguros y } \\
\text { fondos de pensiones }\end{array}$ & 0,0 & 0,0 & 0,1 & 0,4 & 1,9 & 0,7 & 0,0 & 1,0 & 3,9 & 1,5 & 0,8 & 0,4 \\
\hline $\begin{array}{l}65 \text { Seguros, reaseguros y fondos de pensiones, } \\
\text { exc. Seg. Social obligatoria }\end{array}$ & 0,0 & 0,0 & 0,1 & 0,1 & 0,1 & 0,0 & 0,0 & 0,2 & 0,2 & 0,1 & 0,3 & 0,1 \\
\hline $\begin{array}{l}66 \text { Actividades auxiliares a los servicios } \\
\text { financieros y a los seguros }\end{array}$ & 0,5 & 0,3 & 0,8 & 0,9 & 1,0 & 0,3 & 0,1 & 0,9 & 0,5 & 1,3 & 0,4 & 0,3 \\
\hline 68 Actividades inmobiliarias & 0,4 & 0,4 & 0,8 & 1,5 & 0,7 & 0,2 & 0,4 & 0,2 & 0,2 & 0,2 & 0,2 & 0,0 \\
\hline 69 Actividades jurídicas y de contabilidad & 0,6 & 0,4 & 1,0 & 2,3 & 2,1 & 1,3 & 0,1 & 0,1 & 0,3 & 0,3 & 0,3 & 0,3 \\
\hline $\begin{array}{l}70 \text { Act. de las sedes centrales; act. de } \\
\text { consultoría de gestión empresarial }\end{array}$ & 1,5 & 1,2 & 1,2 & 4,0 & 1,6 & 1,4 & 0,1 & 1,0 & 0,1 & 0,6 & 0,7 & 0,5 \\
\hline $\begin{array}{l}71 \text { Serv. técnicos de arquitectura e ingeniería; } \\
\text { ensayos y análisis técnicos }\end{array}$ & 1,7 & 2,4 & 3,6 & 5,6 & 4,6 & 1,9 & 0,3 & 0,3 & 0,8 & 1,0 & 1,4 & 0,5 \\
\hline 72 Investigación y desarrollo & 0,2 & 1,0 & 1,0 & 1,5 & 1,6 & 0,6 & 0,1 & 0,5 & 0,5 & 1,1 & 0,4 & 0,3 \\
\hline 73 Publicidad y estudios de mercado & 1,5 & 1,4 & 1,6 & 3,2 & 1,5 & 0,6 & 1,0 & 1,9 & 1,4 & 2,1 & 0,6 & 0,4 \\
\hline $\begin{array}{l}74 \text { Otras actividades profesionales, científicas y } \\
\text { técnicas }\end{array}$ & 4,1 & 3,3 & 3,2 & 11,2 & 4,8 & 0,6 & 0,5 & 0,7 & 0,5 & 1,5 & 1,1 & 1,1 \\
\hline 75 Actividades veterinarias & 0,4 & 0,2 & 0,2 & 0,7 & 0,5 & 0,6 & 0,2 & 0,0 & 0,0 & 0,1 & 0,1 & 0,0 \\
\hline 77 Actividades de alquiler & 3,2 & 1,7 & 4,6 & 6,6 & 6,0 & 2,1 & 1,8 & 0,6 & 0,8 & 2,5 & 1,7 & 1,5 \\
\hline 78 Actividades relacionadas con el empleo & 1,2 & 0,4 & 1,4 & 1,0 & 1,1 & 0,2 & 0,3 & 0,6 & 0,0 & 0,6 & 1,2 & 0,0 \\
\hline $\begin{array}{l}79 \text { Actividades de agencias de viajes, } \\
\text { operadores turísticos, serv. reservas }\end{array}$ & 0,8 & 0,9 & 0,9 & 2,9 & 3,5 & 0,5 & 0,5 & 0,3 & 0,2 & 0,4 & 2,2 & 0,5 \\
\hline 80 Actividades de seguridad e investigación & 0,0 & 0,1 & 0,5 & 0,8 & 0,7 & 0,1 & 0,1 & 0,1 & 0,1 & 1,1 & 0,2 & 0,0 \\
\hline $\begin{array}{l}81 \text { Servicios a edificios y actividades de } \\
\text { jardinería }\end{array}$ & 1,1 & 0,4 & 0,7 & 1,7 & 2,7 & 1,1 & 0,1 & 0,1 & 0,1 & 0,1 & 0,1 & 0,1 \\
\hline $\begin{array}{l}82 \text { Actividades administrativas de oficina y } \\
\text { otras act. aux. a las empresas }\end{array}$ & 1,4 & 1,2 & 1,3 & 2,4 & 2,0 & 0,6 & 0,8 & 0,5 & 1,0 & 1,0 & 1,3 & 2,1 \\
\hline $\begin{array}{l}84 \text { Administración Pública y defensa; Seguridad } \\
\text { Social obligatoria }\end{array}$ & 0,0 & 0,0 & 0,0 & 0,0 & 0,0 & 0,0 & 0,0 & 0,0 & 0,0 & 0,1 & 0,0 & 0,0 \\
\hline
\end{tabular}




\begin{tabular}{|c|c|c|c|c|c|c|c|c|c|c|c|c|}
\hline 85 Educación & 0,0 & 0,1 & 0,2 & 0,4 & 0,3 & 0,1 & 0,0 & 0,0 & 0,0 & 0,1 & 0,1 & 0,1 \\
\hline 86 Actividades sanitarias & 0,0 & 0,1 & 0,6 & 0,2 & 0,3 & 0,0 & 0,0 & 0,0 & 0,0 & 0,0 & 0,0 & 0,0 \\
\hline 87 Asistencia en establecimientos residenciales & 0,0 & 0,0 & 0,2 & 0,3 & 0,3 & 0,1 & 0,1 & 0,1 & 0,1 & 0,2 & 0,3 & 0,0 \\
\hline $\begin{array}{l}88 \text { Actividades de servicios sociales sin } \\
\text { alojamiento }\end{array}$ & 0,1 & 0,1 & 0,1 & 0,6 & 1,0 & 0,8 & 0,1 & 0,1 & 0,2 & 0,3 & 0,1 & 0,1 \\
\hline $\begin{array}{l}90 \text { Actividades de creación, artísticas y } \\
\text { espectáculos }\end{array}$ & 0,2 & 0,6 & 0,3 & 2,4 & 2,4 & 0,5 & 0,1 & 0,2 & 0,6 & 0,1 & 0,8 & 0,3 \\
\hline $\begin{array}{l}91 \text { Actividades de bibliotecas, archivos, museos } \\
\text { y otras act. culturales }\end{array}$ & 0,1 & 0,2 & 0,3 & 0,4 & 0,3 & 0,1 & 0,0 & 0,1 & 0,0 & 0,8 & 0,1 & 0,0 \\
\hline 92 Actividades de juegos de azar y apuestas & 0,4 & 0,4 & 1,9 & 2,2 & 2,4 & 0,8 & 0,1 & 0,4 & 0,6 & 0,8 & 0,1 & 0,4 \\
\hline $\begin{array}{l}93 \text { Actividades deportivas, recreativas y de } \\
\text { entretenimiento }\end{array}$ & 0,2 & 0,2 & 0,4 & 0,8 & 0,7 & 0,2 & 0,1 & 0,1 & 0,2 & 0,7 & 0,3 & 0,2 \\
\hline 94 Actividades asociativas & 0,4 & 0,4 & 0,8 & 3,3 & 3,5 & 1,3 & 0,1 & 0,2 & 0,4 & 0,7 & 0,8 & 0,3 \\
\hline $\begin{array}{l}95 \text { Reparación de ordenadores, efectos } \\
\text { personales y artículos uso doméstico }\end{array}$ & 9,3 & 1,1 & 0,9 & 2,6 & 3,5 & 1,8 & 1,0 & 0,1 & 1,0 & 0,2 & 0,2 & 0,6 \\
\hline 96 Otros servicios personales & 0,2 & 0,3 & 0,4 & 0,7 & 1,0 & 0,5 & 0,1 & 0,1 & 0,2 & 0,2 & 0,1 & 0,0 \\
\hline $\begin{array}{l}97 \text { Actividades de los hogares como } \\
\text { empleadores de personal doméstico }\end{array}$ & 0,0 & 0,0 & 0,0 & 0,0 & 0,0 & 0,0 & 0,0 & 0,0 & 0,0 & 0,0 & 0,0 & 0,0 \\
\hline $\begin{array}{l}98 \text { Act. de los hogares como productores de } \\
\text { bienes y serv. para uso propio }\end{array}$ & 0,0 & 0,0 & 0,0 & 0,0 & 0,0 & 0,0 & 0,0 & 0,0 & 0,0 & 0,0 & 0,0 & 0,0 \\
\hline $\begin{array}{l}99 \text { Actividades de organizaciones y organismos } \\
\text { extraterritoriales }\end{array}$ & 12,0 & 0,0 & 6,4 & 0,0 & 4,8 & 0,0 & 11,0 & 0,0 & 5,4 & 0,0 & 0,0 & 0,0 \\
\hline TOTAL & 3,1 & 1,6 & 1,8 & 2,8 & 2,2 & 0,9 & 0,4 & 0,3 & 0,5 & 0,6 & 0,5 & 0,3 \\
\hline
\end{tabular}

Fuente: Estadística de Regulación de Empleo (Ministerio de Empleo y Seguridad Social) y EPA (INE). 